\title{
Index for Volume 98
}

AUTHOR AND SUBJECT INDEX. Pages indicating errata are in italic.

Abad, G., S152

Abad, J. A., S9, S89, S122

Abawi, G. S., S63

Abbas, H. K., S9

Abbasi, P. A., S9

Abbasi, S., S138

Abbo, S., 600

Abdollahi, K., S210

Abdullah, N. M., S27

Abel, C. A., S9

Abou Ghanem-Sabanadzovic, N., S137, S138

Abou Jawdah, Y., S9

Abou-Zeid, N. M., S10

Abutilon theophrasti, biocontrol, S204

Abutilon yellow mosaic virus, on maple, $\mathrm{S} 12$

Acacia mearnsii, on pineapple, tannin for control, S31

Acer saccharinum, bleeding canker, Nevada, S166

Acevedo, M., S199

Aceves-Núñez, V. A., S199

Achatz, B., S164

Acidovorax avenae, on watermelon:

—genetics, S169

—and melon seeds, detection assay, S215

- seed infection, $\mathrm{S} 49$

Actinomycete, rhizosphere and rhizoplane, plan effect, S17

Acyrthosiphon pisum, Cucumber mosaic virus vector, transmission efficiency, 1233

Adam-Blondon, A., S13

Adams, G. C., S150

Adams, M. L., S10

Adams, P., S23

Adams-Phillips, L., S195

Adaskaveg, J. E., 205, 1171

Adekunle, A. A., S115

Adhikari, T. B., 101, 702, 969, S10, S11, S113

Adkins, S., S10, S85, S159, S167

Aegilops sharonensis, leaf rust, stem rust, and powdery mildew, resistance, 353

African cassava mosaic virus, East African cassava mosaic Cameroon virus, detection, PCR method, S11

Afsharifar, A., S20, S130

Agave tequilana, heart rot, temperature effect, $\mathrm{S} 99$

Ageratina altissima, umbravirus, detection, S138

Agindotan, B. O., S124

Agriculture

- biodiversity, S1

- changing environment, S2

- experiment station, nation's first, S13

-failure times, $\mathrm{S} 1$

—-food and health role, science policy, S3

— plant biotechnology, public sector scientists, S3

— support for, revitalizing, S2

-water and public health balance, S2

Agrios, G. N., S102

Agrobacterium spp., pathway components, integration role, S161

-A. tumefaciens: acetosyringone response, S13; detection in soil, S103; pathogenicity testing, S106; on walnut, biocontrol with Agrobacterium, S61; on walnut, genotype effect, S66

-A. vitis, on grape, rose, and tomato, biocontrol, 1218

Ahmed, M., S33

Ahonsi, M. O., S10

Aigbe, S. O., S11

Aime, M. C., S184

Ainsworth, T., S43

Alabi, O. J., S11

Albers, J. S., S11

Albin, J., S157

Albugo candida, on Lepidium latifolium, race in
Colorado, S153

Aldwinckle, H. S., S46, S114, S208

Alfalfa (see also Medicago truncatula)

-brown root rot, crop residue effect, S139

- damping-off, biocontrol, S162

—foliar diseases, glyphosate, S54

—leaf spot, enzymes, S165

-Pseudomonas for growth promotion, S176

-Xylella fastidiosa, California, S147

Alfano, J., S42, S76, S78, S158, S193

Alfonso, N. C., S32

Ali, S., 101, 702, 969, S10, S11, S113

Aljaro, A., S135

Alkharouf, N. W., S86

Allaghebandzadeh, N., S11

Allaire, M., S52

Allen, C., 1060, S54, S73, S104, S106, S190

Allen, T. W., 95

Allium spp. (see also Onion)

-bacterial blight, polyphasic characterization, 919

Allsopp, P. G., 810

Almeida, R. P. P., 743, 1093, S81, S124

Almeida-de Leon, H., S162

Almeyda-Becerra, C. V., S12

Almond

- Colletotrichum acutatum, $\mathrm{pH}$ modulation and laser microscopy, 1171

-Prunus replant disease, fumigation, S27

Alnus spp., canker, climate change in Alaska, S192

-A. tenuifolia, Valsa melanodiscus on, inoculation response, S150

Altenbach, D., S115

Alternanthera mosaic virus, clones and symptoms, $\mathrm{S} 90$

Alternaria spp.: on almond, fungicide sensitivity, S116; models and visualization, S149; on pomegranate, black heart, S105

-A. alternata: fungicide resistance, molecular characterizarion, S16; on pistachio, boscalid resistance, 736, S16; on Rumex and Chenopodium spp., bioherbicide agents, $\mathrm{S} 17$

-A. brassicae, on Brassica spp., host-specific toxin, spore origin, 458

-A. solani: on potato, wild and cultivated, 680 ; on Solanum phureja-S. stenotomum, resistance, S140

-A. tenuissima, on sesame seed, S23

Altier, N. A., S124, S162, S176

Alvarado, L., S185

Alvarez, A. M., 1045, S78, S85, S98, S120, S141, S142, S158, S164, S186

Álvarez, B., 59

Alvarez, J. M., 985, S190

Alvarez, R. E., S29

Alyokhin, A., S86

Amaike, S., S12

Amendments, fish emulsion, pathogen suppression, S9

American Phytopathological Society (see also APS history)

—annual meeting abstracts, June supplement, S1

—annual report, 17

- Award of Distinction, 28

- Caribbean Division, abstracts, S199

-Excellence in Extension Award, 29

-Excellence in Industry Award, 30

—Excellence in Teaching Award, 31

-Fellows, 19

-International Service Award, 32

- Noel T. Keen Award, 33

—North Central Division Meeting abstracts, S201

—-Northeastern Division Meeting abstracts, S206 —officers, representatives, and committees, 14

- Potomac Division Meeting abstracts, S214

—Ruth Allen Award, 34

- Southern Division Meeting abstracts, S210

- Syngenta Award, 35

-William Boright Hewitt and Maybelle Ellen

Ball Hewitt Award, 36

Ames, K. A., S167

Amid Motlagh, V., S20

Amiri, A., S12, S25

Ammar, E., S39, S41

Amorim, L., S19, S21, S100, S148

Amphicarpa bracteata, Rhizoctonia solani on seeds, Pseudomonas antagonists, S154

Amyotte, S. G., S12

Anagnostakis, S., S6, S13

Anand, A., S13

Anchieta, A. G., 1340, S185

Ancona, V., S13

Anders, M., S26

Anderson, C., S13

Anderson, M. D., S140

Anderson, N. A., S13

Andrews, J., S56

Andrivon, D., 653

Andropogon gerardii, resistance gene and precipitation, S137

Ane, J., S163

Angel, C. A., S14

Angeli, S. S., S148

Anhalt, M. D., 743

Anikster, Y., 353

Anthurium andraeanum, bacterial blight, resistance genetics, 421

Antonovics, J., S208

Antony, G., S96

Antoun, H., S47, S84

Antunes, R. F., S41

Apaza-Tapia, W., 688

Aphelenchoides fragariae, in ornamental nurseries, $\mathrm{S} 83$

Aphis spp., Cucumber mosaic virus vector, on bean, 1233

-A. gossypii, Papaya ringspot virus vector, 541

Apodaca, J., S73

Appel, D., S13, S157, S187, S210, S212

Apple

—bacteria, culture-dependent isolates, S177

-blue mold, fungicide in storage, S145

—brown rot, epidemiology and injury factors, 79

— disease management, S209

—fire blight, shoot-growth regulators, S102

-flyspeck, symptoms in China, S153

- harpin binding protein 1 gene, fire blight resistance, S147

— organic, alternative fungicides, $\mathrm{S} 42$

- Penicillium expansum, fludioxonil and pyrimethanil resistance, phenotypes, 427

-phytoplasma, resistance, apomictic rootstocks, 153

—postharvest disease, management, S126 scab: fungicides, mummified fruits in New York, S137; resistance, thirty-year study, S201; sanitation and sprays, S68

- sooty blotch and flyspeck: diversity in Brazil, S149; diversity in Serbia and Montenegro, S72; phenology in Iowa, S147

APS history (see also American Phytological Society)

— gender diversity, S6

-leadership and international agriculture, S5

- life science contributions, S6

-milestones, S5

—plant pathology literature, growth, S5 
— public service and outreach, S5

-reflections, S6

-women, minorities, students, S6

-women plant pathologists, S6

Aqeel, A. M., 901

Arabidopsis spp.: Botrytis cinerea pathosystem, Bacillus mojavensis relation, S112; F-box factor, S195

-A. thaliana: hypersensitivity, genetic changes, S55; rhizobacteria, pine origin, protection, 666; rhizobacteria strains, biotic elicitors, 451

Aragon-Caballero, L., 688

Arashida, R., 769

Araya, C., S14, S54, S135

Archibald, D. D., S172

Arenz, B. E., S66

Arias, A., S162, S176

Arias, C., S152

Ariatti, A., S18

Arie, T., 475, S71, S145

Ariss, J. J., S14, S156

Armengol, J., S75, S108

Armillaria spp.: on cherry, diversity, S202; endopolygalacturonase and phenoloxidizing enzymes, S202; root disease, climate change in North America, S192

-A. mellea: on grape, resistance, $\mathrm{S} 22$; survival in green waste, 547; transgene expression, S19

Arnold, S. E., S14

Arntzen, C., S3

Árnyasi, M., 1312

Arriaga, F. J., S109

Arroyo, M., S208

Arundo domax, rhizosphere, Fusarium spp., Texas, S138

Ascochyta rabiei

-azoxystrobin and pyraclostrobin resistance, North Dakota, S205

-pathotypes, subtractive suppression hybridization, S170

Ascomycota, natural groups, systematics, S186

Ashikaga, T., S42

Asimina triloba, sooty blotch and flyspeck, reservoir host, S66

Asparagus, spear and root rot, in Michigan, 1075

Aspen, decline, Colorado, S173

Aspergillus spp.: on grape, ochratoxigenic, Chile, $\mathrm{S} 4$; oxylipins, signaling and regulators, S69; section characterization, protein interaction, S119; section Flavi, on sugarcane, Texas, S57 spores and mycotoxins, seed colonization, S57

-A. cabronarius, on grape, ochratoxin production, S64

-A. flavus: aflatoxin gene cluster, geography, S109; aflatoxin, maize trypsin inhibitor protein, $\mathrm{S} 35$; on almond, navel orangeworm vector, S119; on corn, postharvest colonization, S166; on cotton, pyrosequencing, 282; genomics, pathogenicity, and ecology, S182; on maize aflatoxin, S171; on maize, infection levels, PCR, S106; on maize, pathogenesis, S47; on maize seed, mycotoxin regulation, genes, S212; mutant interaction, S12; sporulation, formulations, S73; vegetative compatibility groups, maize, $\mathrm{S} 103$

-A. fumigatus, ergot genes in common, alkaloid pathway, S214

Atallah, Z. K., S14, S78, S201

Atamian, H., S9

Athinuwat, D., S15

Athukorala, S. N., S15

Atibalentja, N., S15

Atkinson, L., S139

Attanayake, R. P., S15

Augusto, J., S210

Aureobasidium pullulans

—on apple, China, S153

-on grape, ochratoxin A contamination, 1261

Austerweil, M., S159
Austin, C. N., S15

Austin, G., S26

Author index to abstracts, S218

Avanzato, M. V., S16

Avena barbata, crown rust, resistance host, S31

Avenot, H. F., 736, S16

Aversano, R., S97

Avila, F. J., S141

Avila, L., S94

Avila-Adame, C., S16

Avis, T. J., S47, S84, S206

Avni, A., S111

Ayres, A. J., 977

Babadoost, M., S15, S178, S197

Bacchi, L. A., S178

Bacetty, A. A., S16

Bacillus spp.

-B. amyloliquefaciens, on soybean, growth effect, S28

-B. cereus, root-knot nematodes controlled by,

- B. megaterium, biocontrol of pepper bacterial spot and anthracnose, S177

-B. mojavensis, fusaric acid and maize lesions, $\mathrm{S} 16$

-B. phytophthorus, hundred-year history, S7

Backman, P. A., S67, S104, S126, S208

Bacon, C. W., S16, S60, S119

Bacon, R., S158

Bacteria

-biological weapons, letter to editor, 1060

- century of change, S186

-cyclophilin-induced protein, significance, S193

-identification, PCR and electrospray ionization mass spectrometer, 1156

—-soil borne disease suppression, S21

- survival in vegetable production, S191

- systematics, new approach, S7

- type III effectors, innate immunity, S192

—virulence, Hrp system, S192

Bacteriology, century of history, wilt, S190

Badillo-Vargas, I. E., S17

Bae, H., S90

Bai, G.-H., 87

Bai, J., S10

Bai, X., S47

Bai, Y., 529

Bailey, A., S19

Bailey, A. M., 1334

Bailey, B. A., S17, S104, S208

Bailey, T. A., S176

Bajsa, N., S162

Bajwa, R., S17, S112

Baker, C. A., S10, S167

Baker, C. M., S17

Baker, J. C., 1242

Bakker, M. G., S17

Bakker, P. A., S85

Bala, K., S184

Baldo, A. M., S114

Baldwin, C., 1156

Balesdent, M. H., 321

Balint-Kurti, P. J., 315

Ballard, L., 1126

Balogh, B., S169

Ban, J., S17

Banana, foliar and root diseases, Georgia, S84

Banana bunchy top virus

-bananacide effect, S124

-transmission factors, 743

Bandyopadhyay, A., S98

Bandyopadhyay, R., S11, S26

Bandyopadhyay, S., S152

Banihashemi, Z., S18, S108

Bani-Hashemian, S. M., 1199

Banko, T. J., S10

Banno, S., 397

Barak, A. V., S159

Baraoidan, M., S145
Barash, S., S169

Barasubiye, T., S100

Barbaglia, A. C., S18

Barbetti, M. J., 321

Barbier, G., S132

Barceló-Muñoz, A., 815

Bardas, G. A., 443

Bardin, M., 529

Barley

-Fusarium head blight: deoxynivalenol, S58; resistance and mapping, S99

-Fusarium populations, mycotoxin profiles, China, 719

— geminiviruses, Iran, S20

- Mycosphaerella graminicola, nonhost, S202

-Rhizoctonia root rot, tillage and inoculum density effect, 304

- spot blotch, resistance genomic regions, S157

- stem rust, resistance gene allele sequencing, 910

- stripe rust, quantitative trait locus, resistance, 120

Barna, B., 1242

Barnaby, N., S186

Barnard, K., S149

Barnes, C. W., 115, S18

Barnes, J. S., S212

Barnett, K. A., S65

Barrett-Wilt, G., S18

Barrion, A. A., S132

Barriuso, J., 666

Barriuso Maicas, J., 451

Bartz, F. E., S18

Bassanezi, R. B., 977, S19, S21

Bassett, C. L., S114

Batla, M. A., S210

Batzer, J., S66, S72, S118, S147, S149, S156, $\mathrm{S} 174$

Bau, H.-J., 848

Baudoin, A., S40, S214

Baughman, T. A., S210

Baum, T. J., S148, S174

Baumgarten, S., S194

Baumgartner, K., S19, S22, S56, S135

Bayman, P., S19, S43

Baysal Gurel, F., 562, S19

Beachy, R. N., S3

Bean (see also Phaseolus spp.)

-Pythium leak, fungicides, S210

-white mold: resistance screening, S199; survey data, S144

Bean pod mottle virus

—beetle mortality effect, S202

-quantification, S189

—risk assessment, Iowa, S28

-on soybean, infection time and yield, S202

-within-field analysis, Iowa, S29

Bean yellow mosaic virus, on lupin, epidemiological model, 1280

Beard, H. S., S159

Beasley, J. P., Jr., 1066

Beattie, G. A., S37, S55

Beaulieu, C., 1118

Beaulieu, R. A., S20

Bec, S., S20

Becker, J. O., 547

Beckerman, J., S201, S202

Bedendo, I., S48

Beer, S. V., 781, 792

Beet curly top virus

-on Arabidopsis, seed borne gene, S107

- on sugar beet, survey in western USA, 1212

Beet necrotic yellow vein virus, basic reproduction number, model, 239

Beet western yellows virus, on Chinese sugar beet, S65

Begomoviruses, on tomato and tobacco, Yemen, S27

Behjatnia, A., S20 
Behlau, F., S20

Behn, J. L., S20

Beirn, L. A., S20

Beki, E., 69

Bélanger, R. R., S206

Bell, A. A., S21, S103, S151

Bell, J. D., S21

Bellomo, L. M., S101

Bemisia tabaci, Tomato chlorosis virus vector, efficiency, 1340

Bender, C. L., S17, S161

Benitez, M.-S., 562, S21

Bennett, R., S183

Benson, D. M., S132

Benson, M., S83, S116

Bent, A., S21

Bentley, A. R., 250

Bentley, T., 894

Benyon, L., S21

Berbegal, M., S75

Bergamin-Filho, A., S19, S21

Bergemann, S., S135

Berger, P. H., S194

Bergstrom, G. C., S173

Berkett, L. P., S42

Bermudagrass, leaf spot, seasonal activity, S157

Bernache-Pérez, F., S99

Bernal, A., S32, S64, S134, S146

Bernard, E., S86

Bernard, G. C., S22

Bernard, K., 653

Bernardes de Assis, J., 1326

Bernards, M. A., 1179

Bernhold, A., S22

Bernier, L., S126

Berruyer, R., S80

Berry, M. C., S22

Berry, S., S117, S125, S165

Bertetti, D., S64

Bertocchi, D., 148

Bertolini, E., 949

Bertrand, F., 571

Bhat, R., S22

Bi, J., S144

Bian, W., S194

Biehl, B., S40

Bienapfl, J. C., S22, S201

Bieysse, D., 1320

Bignell, D., S76, S191

Biofarming, plant-derived pharmaceuticals, S3

Biological control

— antagonistic bacteria in soilless cultures, S132

- biofumigation in soil, antagonism, S132

-biofungicides and crop yield, organic and sustainable agriculture, S215

- endophytes and pathogens, S97

-fungi for root-knot nematode, screening, S168

-Fusarium wilt of tomato, S78

- Lysobacter enzymogenes, antibiotic complex, 695

- municipal biosolids compost for Pythium ultimum, 1012

- Pantoea agglomerans for Erwinia amylovora, 1136

_plant extracts: on plant pathogens, S92; storage fungi controlled by, S117

_plant products, Korea, S78

-Pythium oligandrum on tomato, bacterial wilt control, 187

—remote sensing, S34

-rhizobacterial strains, biotic elicitors, 451

Biological weapons, pathogenic bacteria, letter to editor, 1060

Biopesticide, risk assessment, S157

Birch, ectomycorrhizae, factors, S82

Bird, D., S40

Birren, B., S185

Bisognin, C., 153

Bitterlin, W., S115
Black, M., S23

Blackwell, M., S183

Blaedow, R. A., S201

Blair, J. E., S23, S206

Blanchette, R. A., S66, S73, S109, S124

Blanco, L. E., S135

Blanco-Meneses, M., S23

Blankenship, E., S204

Bledsoe, S. M., S102

Blenis, P. V., S87, S172

Block, C. C., S92

Blueberry

- anthracnose, molecular mechanism of resistance, S106

- Cylindrocladium stem and root rot, fungicide in Georgia, S65

-fungal pathogens, Chile, S51

Bluhm, B. H., S23

Blumer, S., S101

Blumeria graminis

- on Aegilops sharonensis, resistance, 353

-genome, S193

-on wheat: homeobox-like gene, 1291; weather relation, 609

Blumeriella jaapii, on tart cherry, fungicides, S62

Blyn, L., 1156

Bock, C. H., S23, S41, S121

Boddu, J., S58

Boehm, M. J., 1297, S20, S50, S83

Boerma, H. R., S195

Bohn, M. O., 469

Boiteux, L. S., 618

Boivin, S., S206

Bok, J., S12

Bolton, M. D., S24, S45

Bonde, M. R., S49

Bonello, P., S82, S111, S165

Bonierbale, M., S130

Bonos, S. A., S206

Bordeos, A., S145

Borkovich, K. A., 205

Boroczky, K., S172

Borras, O., S87

Borsick Herman, M. A., S24

Borthakur, D., S85

Boscan, K., S24

Bosco, D., 1093, S159

Bosland, P. W., 867, S130, S139

Bostock, R., S46, S128, S136, S175

Botryosphaeria spp., on almond, diversity in California, S71

Botrytis spp.

-B. cinerea: benzimidazole resistance, genotyping, 397; on cucumber, benzimidazole resistance, cover photo, April; genetic structure, factors in Tunisia, 1271; on grape, sexual recombination, 1312; on snap bean, control, S40; on vegetable crops, anilinopyrimidineresistant strains, 443

-B. elliptica, on lily, systemic resistance induced, 830

-B. fabae, on Vicia faba, chitinase, S10

-B. squamosa, on onion, epidemic, management, 38

Bottner, K. D., S88

Bou Azza, K., S50

Bounds, R., S116

Bouquet, A., S13

Bové, J. M., 337, 977

Bowatta, D. R., S114

Bowen, K., S24, S30, S152, S212

Bowersox, V. C., S18

Boyd, L., S166

Brabec, D., S171

Bradeen, J. M., S57, S97, S136

Bradley, C. A., S24, S123, S146, S167, S172, S205

Bradshaw, T. L., S42

Brandt, N., S25
Brannen, P., S12, S25, S65

Brantner, J., S25, S172

Brassica spp., yellows, new forma specialis, 475

-B. napus, Verticillium wilt, resistance loci, 215

Brauer, K. N., S25

Breathnach, J. A., S167

Brennan, J., 69, S25

Brenneman, T., S36, S144, S210, S212

Brenneria rubrifaciens, on walnut, synthase gene, S101

Breth, D. I., S208

Brettin, T., S142

Brewer, M. T., S25

Briceño, A., S24

Briceno, E. X., S51

Brière, S. C., S75

Brissey, L. M., S48

Brlansky, R. H., S199

Broders, K. D., S26, S50, S51, S165, S201

Brodhagen, M., S57

Bromfield, E., S154

Bronson, J. J., S26

Brooks, S., S26

Broome, J. C., S26

Brown, D., S114

Brown, J. K. (Ariz.), S27, S70, S120

Brown, J. K. M. (U.K.), 128

Brown, L. G., S27

Brown, R., S26, S35

Brown, S. L., 1066

Browne, G. T., S22, S27, S47, S141

Browning, J., S102

Brubaker, C. L., 296

Brubaker, H., S27

Bruck, D., S94

Bruckart, W. L., S214

Brueggeman, R., 910

Brumbley, S. M., 810

Brunings, A. M., S27, S28

Brunner, P. C., 752

Bruns, H., S9

Bryson, P. K., S68

Buck, J., S143

Buckley, B., S195

Budowle, B., S186

Buell, C., S38

Buensanteai, N., S28, S127

Bunting, M. L., S159

Burdon, J. J., 296

Burgess, L. W., 250

Burgos, M., S28

Burkholderia spp.: antifungal activity, transcriptional regulators, S63; in soil, tillage effect, S92

-B. andropogonis, on citrus, relation to Xanthomonas citri, S131

Burlakoti, R. R., 101, 969, S10

Burmester, C. H., S109

Burnes, T. A., S73

Burnett, A. L., S207

Burns, J. K., S55, S81

Burr, T., S15, S44, S45, S56, S208

Bussan, A. J., S62

Bussey, K. E., S12

Butler, D. N., S28,

Butôt, R., S103

Butzler, T., 1233

Byamukama, E., S28, S29, S94, S189, S202

Caasi, O. C., S29

Cabbage

-Alternaria black spot, biocontrol, S208

-Phytophthora root rot, Kentucky, S212

-soil-borne wilt, antagonist control, S128

Cabrera, I., S53

Cabrera, M., S29, S137

Cabrera, O. G., S29

Cacao (see also Theobroma cacao)

- endophyte, witches' broom relation, S104

Cadieux, M., S158 
Cadle-Davidson, L., S29

Caesar, A., S30

Caesar, T., S30

Caesar-TonThat, T., S87

Cahalane, G., S25

Cai, G., 823

Cai, J., S179

Cai, X., 926

Calderon, C., S30

Calderon-Urrea, A., S175

Caldwell, K. S., S195

Calla, B., S30

Calvert, L., S197

Camargo, L. A., S148

Camp, A. R., S30

Campbell, B., S16

Campbell, H., S24, S30

Campbell, K. B., 1126

Campbell, K. W., S24

'Candidatus Liberibacter asiaticus'

—antiserum development, S47

-on citrus: China, S35; cultivation, S142; detection in Florida, 387; PCR detection, 592; yellow shoot, Florida, S48

- genome, S142

-multilocus sequence typing system, S215

-on periwinkle and dodder, transmission, S181

Candolfi-Arballo, O., S67

Canola, diseases affected by preceding crops, S74

Canteros, B. I., S30, S60, S137

Cantú, M. D., 1084

Cao, T., S31

Capote, E., S135

Capsicum spp., Phytophthora capsici, survival in Peru, 688

-C. annuum: new phytoplasma, S130; Phytophthora root rot, race-specific resistance, 867

Carbone, I., S23, S109, S122

Cárdenas, M., S134

Cardina, J., S19

Cardinal, A. J., 315

Carisse, O., 38

Carlisle, C. M., S114

Carlos, W. J., S166

Carnation necrotic fleck virus, associated virus, S78

Carputo, D., S57, S97

Carrascal, A. K., S200

Carrilho, E., 1084

Carrillo, M. C., S31

Carris, L. M., 413

Carrot

- aster yellows, strain detection, S55

-cavity spot: detection, S93; pigmentation and weather, S101

-leaf blight, nitrogen and fungicide balance, S101

Carson, M. L., S31

Carta, L., S111

Carter, L. L. A., 992

Carter, M. L., S95

Carvalho, R., S31

Carya cardiformis, stem canker and bark necrosis, cause, S77

Castello, J. D., S110

Castiblanco, L. F., S32

Castilla, N. P., S32

Castillo, J. D., S32

Castillo, P., 709, S77

Castillo, R., S199

Castle, A. J., 673

Castoria, R., 1261

Castroverde, C. D., S133

Caswell-Chen, E., S178

Cating, R. A., S32, S119

Caulimovirus spp.

—on Dahlia variabilis, new species, S119

— genomic regions, assay, S120

Cavatorta, J. R., S33
Cavinder, B., S33

Cell death, defense pathway, rice and Arabidopsis, S194

Celtis accidentalis, chlorosis, lexivirus, S94

Celton, J., S114

Cepero, M. C., S94

Ceratocystis fagacearum

-on oak, control, S77

—on red oak, propiconazole, S201

Cercospora spp.

-C. beticola: genotype analysis, Iran, S138; on sugar beet, benzimidazole resistance, S115; on sugar beet, management, S80; on sugar beet, survey in three states, S77

-C. coffeicola, on coffee, vegetative compatibility, 1205

-C. kikuchii, on soybean, population structure, 823

-C. sojina, on soybean, Ohio, $\mathrm{S} 43$

- C. zeae-maydis, on maize, light effect, S23

Cereal

-Pythium and Rhizoctonia spp., ecology, S187

-rust collections, history, S183

Ceresini, P. C., 932, 1326, S188

Cervantes, F. A., S190

Cha, B., S120

Cha, J., S39, S74

Chacko, N., S33

Chacon, O., S87

Chaijuckam, P., S33

Chambliss-Bush, S., S177

Chamswarng, C., S97

Chan, S.-J., 848

Chanda, A., S120

Chanda, B., S33

Chandra-Shekara, A. C., S74

Chang, C., S33

Chang, J., S34

Chang, P., S34, S214

Chang, S. (Ill.), S34, S119

Chang, S. W. (Mass.), 108, S207

Chang, S. W. (Korea), 1297

Chao, C., S34

Chapara, V., S34

Charkowski, A., S58, S59, S62, S73, S82, S98, S143

Charlton, N. D., S34

Chatfield, J., S201

Chau, J., 1093, S159

Chaudhary, S., S34

Chaverri, P., S186

Chen, C. (Calif.), S37

Chen, C. (Iowa), S37

Chen, C.-Y. (Taiwan), 830

Chen, D., 215

Chen, F., S114

Chen, J. (Pa.), S176

Chen, J. C. (Calif.), 960, , S35, S150, S183, S190

Chen, K.-C., 848

Chen, L. (China), 781, 792

Chen, M.-H., 1012, S36

Chen, P., S35

Chen, S., S90, S148, S154

Chen, W., S15, S35, S114, S170

Chen, X. (Ga.), S36

Chen, X. M. (Wash.), 120, S38, S41, S144, S166, S177

Chen, Y. (Wis.), S37

Chen, Y.-K. (Taiwan), 848

Chen, Z., S26, S35, S120

Cheng, D. W., S37

Cheng, P., S38

Cheng, Y., S37

Cheng, Z., 792

Cheong, S., S121

Cherry, K., S38

Cherry, wood-rot, Japan, S145

Chestnut

_blight, recent advances, S7 —hundred-year history, S6

-rotten fruit disease, causes, S168

Cheung, F., S38

Cheung, W. Y., 215

Chibucos, M., S40

Chica, N., S200

Chiroleu, F., 919

Chitinase, citrus sudden death disease inhibitor, 1084

Chitrampalam, P., S38

Cho, B., S39, S74, S81, S178

Cho, J., S39, S117

Cho, K. H., S18

Cho, M., S83

Cho, S., S39, S81

Choi, H., S39, S83

Choi, K., S78, S88

Choiseul, J., S25

Chowpongpang, S., S47

Chriscoe, S., S215

Christ, B. J., 405, S140

Christensen, S. A., S210

Christopher, M., S215

Chromobacterium sp., chitinase effect, S39

Chrysantheum, white rust, status in USA, S103

Chu, A. L., S97

Chulze, S. N., S109

Chung, C., S39

Chung, G., S81

Chung, H., S86, S120

Chung, W., S76

Churchill, A., S86

Ciampi, M. B., 932

Cicer spp., Didymella rabiei on, sympatric pathosystems, 600

$-C$. arietinum, Fusarium wilt and root-knot nematode, interactions, 709

Cilas, C., 1320

Ciomperlik, J. J., S39

Ciotola, M., S158

Cisneros, F. M., S39

Citrus

- 'Candidatus Liberibacter asiaticus', vector, detection, S21

-canker: eradication program, S196; HorsfallBarratt scale, S23; image analysis, S41; resistance screening, S55; severity estimates, S23; soil chemical control, S55

- canker and huanglongbing, survey, Texas, S138

- disease resistance, gene transformation, S85

- green mold, fungicide resistance, 205

- greening: detection and management in Florida, 387; new disease for Americas, S199; PCR detection, 592

-huanglongbing: Asiatic strain, S138; association with pigeon pea witches'-broom, Brazil, 977; insecticides, Brazil, S21; huanglongbing, metagenomics, S56; phylogenomics, S47

-huanglongbing disease, gardens and nurseries, S129

—pests, model system, S27

- postbloom fruit drop, anthracnose, 345

- stubborn disease, epidemiology in California, S190

- sudden death disease, proteomic analysis, inhibitors, 1084

— viroid V, new variants, diagnosis, 1199

Citrus greening disease, management, Brazil, S97

Citrus sinensis, 'Candidatus Liberibacter asiaticus', host response, S81

Citrus tristeza virus

—diversity in California, S178

- recombination in genome, S174

Ciuffetti, L. M., S97

Civerolo, E., S35, S37, S47, S190

Cladosporium fulvum, lysine motifs, S45

Clarke, B. B., S20, S43, S185, S207

Clary, M., S139

Clavibacter michiganense 
- on potato, detection test, S59

-on tomato, bioluminescent construction, S174

- tomato seed transmission, S78

Claybrooke, R., S18

Clayton, M., S188

Clement-Mathieu, G., S206

Cleveland, S., S160

Cleveland, T., S26, S35

Clinton-Cirocco, K., S177

Clonostachys rosea, on strawberry, biocontrol, S41

Clough, S. J., S30, S129

Coaker, G., S193

Cobb, A. C., S40

Cochliobolus spp.

-C. hetrostrophus, on corn, resistance loci, inbreds, 315

$-C$. sativus, gene silencing system, transformation, $\mathrm{S} 88$

Coffee

- Cercospora coffeicola, genetics and vegetative compatibility, 1205

-leaf rust, management in Kenya, S77

Coffey, M., S98, S206

Coffman, V. A., S127

Cohen, S. D., S40

Colburn, G. C., S40

Colburn, J. L., S105

Colcol, J. F., S40, S214

Collado-Romero, M., 1019

Colletotrichum spp.: on grape, epidemiology, $\mathrm{S} 170$; on grape, population structure, S170; isolate variation, worldwide, S53; on mango, species roles, S155; mobility assay, heteroduplex pattern, $\mathbf{S} 69$

-C. acutatum: on almond, $\mathrm{pH}$ modulation, laser microscopy, 1171; on citrus, fruit drop, 345; on grape, China, S153; on strawberry, detection, $\mathrm{S} 22$

-C. cereale: fungicide sensitivity, North Carolina, S159; on grass and cereal, turfgrass relation, S43; thiophanate methyl resistant, S178

-C. coccodes: on potato, resistance, S62; vegetative conpatibility groups, variability, 901

-C. fragariae, on strawberry, other hosts, S96

-C. gloeosporioides: on avocado, virulence regulators, S107; on strawberry, epidemiology, S129

-C. gossypii, on cotton, Bacillus for control, S102

-C. higginsianum, on Arabidopsis, glycerol metabolism, S33

Collins, D. J., S210

Collmer, A., S40, S90, S192

Collmer, C. W., S40

Colombo, M., S41

Colpetzer, K. E., S142

Colucci, S. J., S68

Columbine, powdery mildew, cross-inoculation, cover photo, May

Compost

-municipal, Pythium suppressed by, S36

- pathogen survival, ground green waste, 547

Coniothyrium minitans, $\mathrm{G}$ ptotein, effect on Sclerotinia spp., S38

Connell, L., S49

Conner, K. N., S41

Conti, F., S208

'Continental Famine', causes in Europe, 1846-7, S187

Conway, W. S., S77

Cook, A. Z., S23, S41, S121

Cook, D. R., S163

Cook, R. J., S6

Cooke, B. M., 69

Cooke, P., S142

Cooksey, D., S144

Cooley, D. R., S206

Cooper, B., 1126

Copes, W. E., S10
Coplin, D. L., S41

Coram, T., S41, S166

Cordia sebestena, tar spot, USA occurrence, S119

Cordoba Cañero, D., 509

Cordova-Tellez, L., S146, S179

Corn (see also Maize)

- ear rot, insect damage relation, S25

- endoparasitic nematodes, roots, S20

-foliar fungicide response, meta-analysis, $\mathrm{S} 123$

- hybrids, fungicides for, S24

—potential pathogens, Wisconsin, S75

- smut, aflatoxins and fumonisins, S9

- sweet, Stewart's wilt resistance, 469

Cornelius, K., S53

Correa, V. R., S41

Correa-Victoria, F. J., S92

Correll, J. C., 894, S44, S53, S92, S163

Cortesi, P., 148

Cortez, A. A., 1340

Costa, A. M., S46

Costa, M. J. N., 932

Cota, L. V., S41

Cotton

-aflatoxins, Aspergillus flavus strains, pyrosequencing, 282

-Bacillus seed and boll rot, insect transmission, S21

-Fusarium oxysporum, virulence evolution, serial passage, 296

-reniform nematode, tillage and planting date effect, S151

- seed and boll infection, stink bug vector, $\mathrm{S} 103$

-Verticillium dahliae, enzymes, S155

—wilt, antagonists, S64

Cotton leaf crumple virus, gene silencing vector, $\mathrm{S} 70$

Cotty, P. J., 282, S57, S73, S103, S117, S182

Coutinho, T., 1060

Covarrubias-Ramirez, J., S162

Cover photo

—asparagus, Phytophthora sp., symptoms, October

-Botrytis cinerea on cucumber, benzimidazole resistance, April

—columbine, powdery mildew, cross-inoculation test, May

- Cucurbit leaf crumple virus, symptoms, September

-Ipomoea spp., Uganda, June

- Leptosphaeria biglobosa, on oilseed rape, March

-Pelargonium spp., stem inoculation, August, 1052

— phytoplasma, phyllody on Japanese hydrangea, July

-Rhizoctonia solani, infection on potato, November

- Superoxide dismutase in Botrytis cinerea, December

-Thekopsora areolata, on Norway spruce, January

-Verticillium dahliae, on olive, Spain, February

Cowger, C., 752, S122

Cox, K., S42, S137, S163, S202

Coyle, C. M., S214

Crabill, E. P., S42

Crane, C., S77

Craven, K. D., S21, S34, S59, S89

Creamer, R., S42

Cregan, P., S117

Crespo, J. A., S87

Crespo, N., S42

Crohn, D., 547

Cromwell, M. L., S42

Cronartium spp.

-C. quercuum, avirulence gene, positional cloning, S13

-C. ribicola: response over century, S187; on Ribes sp., rainfall effect, S113; on white pine, histopathology, S73; on white pine, resistance in western USA, 413

Crop rotation, corn, cotton, and peanut, diseases and nematodes, S30

Crouch, J., S20, S43, S126

Crouse, P. W., S127

Cruz, C., S43, S202

Cruz, L. F., S43

Cryphonectria parasitica

-on chestnut, Korea, S120

- cryparin gene, analysis, S86

-virulent and hypovirulent strains, canker development, S216

Csinos, A. S., 196, S43, S84, S177, S210

Cubeta, M. A., S18, S43, S79

Cucumber

-bacterial wilt, management, S67

- Pseudoperonospora cubensis, interaction study, S140

-Pythium damping-off, Trichoderma seed treatment, S75

-Zucchini yellow mosaic and Cucumber green mottle mosaic viruses, Korea, S88

Cucumber mosaic virus

-on bean: aphid dispersal activity, S144; aphid transmission efficiency, 1233

—on bean and pepper, genetic diversity, S114

-on bell pepper, symptoms, S99

- expression vector, protein, S55

Cucumis melo, Melon necrotic spot virus, inability to infect, 1165

Cucurbit

-Phytophthora spp., Japan, S67

—-seedborne pathogen assay, detection, S91

-streptomyces, $\mathrm{pH}$ effect, S58

Cucurbit leaf crumple virus

- recovery, adaptive antiviral response, RNAs, 1029

- symptoms, cover photo, September

Cucurbit yellow stunting disorder virus

- on cucumber, virus movement, S9

- on cucurbit, detection methods, S120

Cuesta, P., S107

Cui, J., S153

Culbreath, A. K., 196, 1066, S36, S115, S210

Culture collection

—changes, S7

—fastidious collections, features, S183

- system improvement, S183

Cummins, D., S25

Cuomo, C., S185, S193

Cuppels, D. A., S43

Cursino, L., S44, S45

Curtis, C. R., S50

Curvularia spp., on zoysiagrass, first in USA, S208

Cyrtomium falcatum, virus, new species, S162

Cystora sp., on stone fruit, management, S126

Czeglédi, L., 1312

Czymmek, K., S80

Daane, K. M., 1093, S147, S156, S159

Daayf, F., S66

Da Graca, J. V., S85, S98, S131

Dahlia mosaic caulimovirus, on wild dahlia, Mexico, S50

Dai, Y., S44

Damann, K., S35

Damicone, J. P., S210

Damsteegt, V., S142

Danehower, D. A., S18

Dang, P. M., S44

Darby, H. M., S42

D'Arcy, C. J., S44, S49

Daròs, J. A., 337, 1199

Das, M. K., 282

Datnoff, L. E., S27, S28, S69

Daughtrey, M. L., S14, S51

Daugovish, O., 547 
Davelos Baines, A., S34, S58

David, A. J., S73

Davidson, J. K., 1226

Davidson, J. M., 860

Davidson, R. M., S44

Davidson, S. L., S24

Davis, E. L., S132, S148, S174

Davis, J., S13, S23

Davis, M., S78, S93

Davis, R., S33, S44, S168

Davlin, J., S202

Dawson, W. O., 592, S174

Day, B., S83, S106, S140

Deahl, K. L., S62

Dean, R., S22, S40, S43, S114

de Cock, A. W. A. M., S184

De Curtis, F., 1261

Dee, M. M., S118

de Felice, D. V., 1261

DeFigueiredo, P. J., S13

Deford, R., S202

Dehne, H.-W., 760

de Jonge, R., S45, S185

de Kievit, T., S15

de la Cerda, K., S178

De La Fuente, L., S44, S45, S176

De La Torre, C., S45

de los Reyes, B. G., 894

Del Ponte, E. M., S149

Del Rio, L. E., S128

del Río, M., S119

Delaney, D. P., S146

Delaney, M. A., S146

Delemarre, F., 942

Delgado, J. A., S45

Delgado, P., S45

Demographics, hiring and graduation rate, USA, S56

Demuren, A. O., S10

Deng, X., S35

Deniel, F., S132, S161

Denny, T., 1060

de Oliveira, J. L., S178

Deom, C. M., S107

Derie, M. L., S48

Desaulniers, N., S184

Descender, S., 653

Dethoup, T., S97

Detter, C., S142

DeVries, R. M., S179

Dewdney, M. M., S46

De Wolf, E., S113, S172

Diagnostics

-forensic science, S186

-historical perspective, S185

-Molecular Diagnostic Laboratory, USDA, S152

-PCR-based detection, nucleic acid extraction, S89

Dianese, A. C., S46

Dianese, J. C., S46

Diaphorina citri, citrus greening vector, Florida, 387

Diaporthe spp.

-D. helianthi, on sunflower, factors, $\mathrm{S} 123$

-D. phaseolorum, on soybean, aggressiveness components, S95

Diaz, G. A., S46

Diaz, M., S156

Diaz-Arias, M. M., S46

Dibar, E., S162

Dickeya dadantii

_ biofilm formation and plant attachment, S73

—-secretion inhibitor, shared with Yersinia, S143

Dickman, M., S193

Dickstein, E. R., S32

Didymella spp.

-D. bryoniae: on cucurbits, detection, S91; on watermelon, boscalid resistance, S151

-D. rabiei, on Cicer spp., ecological affinities, 600
Diéguez-Uribeondo, J., 1171

Dietzgen, R., S98

Díez-Navajas, A. M., 776

Diggle, A. J., 1280

Dileo, M., S46, S128

Dillard, H. R., S30, S40, S144

Dill-Macky, R., S58

Ding, S.-L., S202

Dinkla, I., S103

Dionne, A., S47, S84

Diplocarpon rosae, on roses, resistance genetics, S170

Diplodia spp., on red and jack pine, Minnesota, S11

-D. pinea: on Austrian pine, terpenes, S165; on red pine, inoculum longevity, S110

Discula quercina, on oak, mini-review, 380

Dissoconium mali, on persimmon, flyspeck signs, S153

Dixon, E., S143, S212

Dixon, R. A., S160

Doane, S. R., S10

Dobinson, K. F., S12, S90, S184, S185

Doddapaneni, H., S47

Dolezal, A. L., S47

Dolja, V. V., S78

Doll, D. A., S27, S47

Dollet, M., S199

Domenech, J., 451

Domier, L. L., S47

Domínguez, M., S135

Dominiak-Olson, J., S210, S212

Donahoo, R., 688

Dong, H., 781, 792

Dong, X., S103

Dong, Y.-H., 87

Donnua, S., S47

Donofrio, N. M., S100, S108, S216

Doohan, F. M., 69

Dorrance, A. E., S26, S43, S50, S51, S117, S125, S165, S201, S202, S204

Dotray, P. A., S210

Double, M. L., S216

Douches, D., S49

Douglas, S., S13

do Vale, F. R., S141

Dowell, F. E., S167

Downer, A. J., 547

Downie, A. J., S163

Downie, B., S33

Drader, J., 1156

Drader, T., 910

Draper, E., S201

Draper, M. A., 999

Dreaden, T. J., S48, S70

Dreher, T. W., S160

Drijber, R., S204

Druffel, K., S50, S119, S120

Druzhinina, I. S., 1312

Dry, I. B., S13

Du, L., 695

Duan, Y., S21, S48, S181

Duarte, V., S48

Dubrovsky, L., S52

Duerkop, B. A., S101

Dufault, N. S., S48

Dugan, F., S15, S183

Dulcamara mottle virus, Turnip yellow mosaic virus comparison, $\mathrm{S} 160$

Duncan, S. M., S66

Dung, J. K., S48

Dunkle, L. D., S23

Dunlap, C. A., S147

Durairaj, S., S49

Duran-Martinez, C., S127, S199

Duran-Vila, N., 337, 1199

Durham, T. C., S18

Dute, R. R., S99

Dutilleul, P., 1118 du Toit, L. J., S48, S142, S163

Dutta, B., S49

Duy, J., S49

Eager, T., S173

Eamvijarn, A., S97

Eastburn, D. M., S44, S49, S198

Eastwell, K., S120

Echinochloa spp., Fusarium fujikuroi, 992

Ecology

—pathogen populations, sources, S188

- sampling methods in communities, S188

Economics, plant diseases and global setting, S188

Edmunds, B. A., S49, S68

Education (see Teaching)

Edwards, A., S163

Edwards, H., S49

Edwards, M. C., S93

Edwards, S. G., 69

Egel, D. S., S133, S170

Egeland, L., S173

Eggenberger, A., S65

Egusa, M., 458

Ehrenfried, M. L., 1126

Ehrlich, K. C., 282

Eichhornia crassipes, biocontrol, Nigeria, S115

Eid, S., S9, S50

Eikemo, H., S125

Eini Gandomani, O., S20

Eiras, M., 1199

Eisenback, J. D., S50, S122, S216

Eisley, B., S202

Elad, Y., 270

Elateek, S. Y., S50

Elibox, W., 421

Elkins, R., S26

Ellendorff, U., S185

Elliott, J. L., S109

Ellis, M. L., S50, S51, S165, S202

Ellis, S. D., S50

Elmer, W. H., S51, S207

Elofsson, M., S143

Elphinstone, J., 1060

El Rassi, I., S50

El-Tarabily, K., S51

Enciso-Cabral, G., S127

Endophytes

- cool-season grasses, protoplast fusion, S89

-Espeletia spp., pathogen effect, Colombia, S94

-fungal, loline alkaloids, S52

-oak, mini-review, 380

Engelbrecht, C., S167

English, J. T., S52, S62

Enterobacter cloacae

—biocontrol of Pythium ultimum, S172

-on onion, temperature, bulb decay, S142

Enya, J., 475

Epichlö̈ sp.

-endophyte on grasses, PCR primers, S152

- endophytes, anastomosis, S34

Epidemics, crop yield, S188

Epidemiology

-binary power law, hop powdery mildew, 1107

- host growth effect, S207

_plant viruses, history, S188

Eradication, management practice, S196

Erhardt, C., S140

Erich, S., S86

Errata

—vol. 96, no. 8 (2006), 846, 956

—vol. 97, no. 7 (Suppl), 2007, S200

-vol. 98, no. 5 (2008), 504, 956

—vol. 98, no. 8 (2008), August cover photo, 1052

Erwinia spp., on pear, species competition, 673

-E. amylovora: on apple, gene-specific markers, $\mathrm{S} 114$; on apple, resistance and stress relation, S113; on apple, temperature effect, S46; on apple and pear, biofilm formation, S83; on 
apple and pear, molecular markers, PCR fingerprinting, 260; bacterial antagonists and oxytetracycline, S151; detection, S156; Pantoea agglomerans antibiotic to, 1136; on pear, reactive oxygen species, $\mathrm{S} 22$; on pear and apple, epiphytic phase, S76; Rcs phosphorelay system, S165; signal transduction system, S180; signal transduction system, molecular characterization, S111; strain differences in Iran, S108; streptomycin resistance, Michigan, S101; streptomycin-resistant strains, New York, S208

-E. chrysanthemi, on orchid, Florida, S32

Erysiphales, anamorphs, identification in Puerto Rico, S157

Erysiphe spp., on lentil and pea, Pacific Northwest, S15

-E. necator: ascospore release, seasonal, S109; fungicide resistance, S40; on grape, bud overwintering, Italy, 148

Escherichia coli, on lettuce, storage temperatures, S152

Eskandari, F. M., S214

Esker, P., S75, S179, S188

Esmenjaud, D., 942

Espinoza, J. G., S51

Esquivel, J. F., S103

Estevez de Jensen, C., S52, S134, S162, S163, S164

Eubanks, M., S110

Eucalyptus spp., host jumping and disease, Uruguay, S124

Eujayl, I. A., 1212, S152

Eutypa lata, on grape:

- geographical diversity in North America, S135

— virulence factors, 222

Evans, C. K., S79

Evans, R. G., S87

Eveillard, S., 977

Evenson, C., S77

Everts, K. L., S173, S180

Ewing, L., S69

Exserohilum rostratum, on tigergrass, Florida, S27

Extension, wikis for information communication, S68

Faber, B., 547

Fabregar, E. G., S108

Fabritius, A., S52

Fadda, Z. G. N., 337

Fan, Z., S37, S155

Fang, G., S52

Fang, X., 1179

Fang, Z. D., S52, S62

Faris, J. D., 488, S93, S180

Farokhi Nejad, R., S138

Farrell, R. E., S114

Farrell, R. L., S66

Fassio, A., S123

Faulkner, J. R., S52

Fayad, F., S100

Fazza, A. C., S148

Feau, N., S52

Fedorova, N., S43

Feechan, A., S13

Fegan, M., 1060

Fekete, É., 1312

Feliciano, M., S53

Fellers, J. P., S43

Feng, C., 894, S53

Feng, J., 803, S215

Feng, S., S179

Fengler, G. W., S178

Fermin, G. A., S24

Fermin Munoz, G., S134

Fernandez, L., 1093, S16, S159

Fernández-Muñoz, R., 618

Fernando, D., S15, S59

Ferrandino, F. J., 492, S207
Ferro, H. M., S102

Fessehaie, A., S10

Festuca arundinacea, Rhizoctonia solani and $R$. zeae, digital image analysis, S154

Fichtenbauer, D., S137

Fichtner, E. J., S53, S121

Fieland, V., S121

Field, C., S2

Fievet, V., 942

Figueiredo, J. F., S53

Figueroa-Lopez, P., S54

Fiji disease virus, on sugarcane, rearing of vector, 810

Finn, C., S96

Fiore, N., S54

Flanagan, R. C., S141

Fleischer, S. J., 1233, S67

Fletcher, J., 960, S5, S17, S104, S107, S190

Flint, M. L., S82

Florea, S., S54

Flores, D., S138

Flores, R., 337, 1199

Flores-Cruz, Z., S54

Flores-Olivas, A., S162

Floriculture, disease stress, silicon use, S93

Floyd, C., S97

Floyd, L. E., S54

Fones, H., S191

Fonsah, E. G., S84

Foote, P., S152

Forbes, G., S149

Forest, urban, post-hurricane effect, New Orleans, S210

Förster, H., 205, 1171

Fossdal, C. G., 51

Foster, G. D., 1334, S19

Foster-Hartnett, D., S54

Fourie, G., S108

Fournier, E., 1271

Fradin, E., S185

Fraedrich, S. W., S70

Franc, G. D., S115

Francis, M. I., S55

Francki, M. G., 886

Franco-Molano, A. E., S94

Frankliniella occidentalis, Tomato spotted wilt virus vector, glycoprotein as inhibitor, 45

Frantz, J., S27, S93, S116

Frate, C., S114

Frederick, L., S6

Frederick, R. D., S122

Freeman, B. C., S55

Freeman, S., S57

French-Monar, R. D., S211

Frenkel, O., 600

Freshour, G., S163

Frey, P., S52

Frias-Trevino, G. A., S162

Friedt, W., 215

Friesen, T., S93, S180

Frost, K. E., S55

Fry, W., S130

$\mathrm{Fu}, \mathrm{D} ., \mathrm{S} 55$

Fu, Z., S76, S78

Fubuh, A., S140

Fuchs, M., S116

Fuentes-Davila, G., S54

Führer, M. E., 260

Fujii, H., 464, 1038

Fujiki, M., S55

Fujimura, M., 397

Fujiyoshi, P., S22, S135

Fukuda, K., S145

Fukumori, F., 397

Fulbright, D. W., S129

Fungi, identification history, S186

Fungicides (general) (see also Fungicides, specific)

-Botrytis cinerea resistance, genotyping, 397 -fludioxonil and pyrimethanil resistance, Penicillium expansum on apple, 427

- foliar applications, corn production effect, S211

-fungicide and nematicide tests, 60 years of data, S133

-Monilinia fructicola, resistance phenotypes, 230

-resistance, method for identifying, S202

-tank-mix field treatments, bacterial contamination, S216

-triazole-based, Fusarium head blight of wheat, meta-analysis, 999

-turfgrass, dollar spot, resistance, 1297

—vegetable crop management, S173

Fungicides (specific) (see also Fungicides, general)

-acibenzolar-S-methyl, pear scab induced by, 585

- anilinopyrimidine, Botrytis cinerea resistance, 443

-boscalid, pistachio to Alternaria alternata, resistance, 736

-fludioxonil and pyrimethanil, Penicillium digitatum resistance, mechanisms, 205

-strobilurin, seed treatment, low temperature stress effect, S212

-Taegro, soilborne pathogens, S60

Funnell, D. L., S56

Fusarium spp.: genomic comparisons, S96; mycotoxins, detoxification, S63; nitrogen regulatory gene, S203; seed-borne on sweet corn, light effect, S106; seed treatment and photosynthesis, S134; on soybean, Iowa, S46; on soybean, Minnesota, S22; on soybean, root colonization and soil moisture, S105; wheat head blight, environment, 69

-F. asiaticum, on barley, species comparisons, China, 719

-F. circinatum, on pine, spore deposition, California, 137

-F. fujikuroi, on California rice and water grass, population structure, 992

- F. graminearum: ascospore discharge, mechanism, S33; model strains, S20; nivalenol production, genetics, S56; on potato, deoxynivalenol, S45; on soybean, fungicides, S51; species complex, molecular characterization, Japan, 159; transcriptome, infection and toxin, S122; transducin beta-like gene, S203; on wheat, deoxynivalenol and moisture, S58; on wheat, fungicides for blight and deoxynivalenol, metaanalysis, 999; on wheat, quantitative trait loci, 87; on wheat, Tween 20 effect, S79; on wheat and barley, defense peptides, S62; xylases, characterization, S103

-F. mangiferae, on mango, bud mite interaction, S57

-F. oxysporum: on banana, molecular marker, S34; on banana, race 4 in Philippines, S108; biocontrol of weeds, S139; on Brassica spp., new forma specialis, Japan, 475; on chickpea, mating type in Mexico, S161; on chickpea, nematode relation, 709; on Coreopsis verticillata, pathogenicity and phylogeny, S51; on cotton, fusaric acid biosynthesis, S151; on cotton, virulence evolution, serial passage, 296; laccase genes, analyses, 509; macroconidium formation, nitrite reductase gene, 1099; microsatellite markers, S69; sexuality restoration, S71; on watermelon, resistance, S180

-F. pseudograminearum, Australian population, genetics, 250

-F. solani: on pea, resistance, mini-review, 372 ; on soybean, damping-off, 113; phylogenetics, human infection, S146

-F. verticillioides: biosynthesis of $\mathrm{FB}_{1}, \mathrm{~S} 81$; fumonisin $\mathrm{B} 1$ production, nitrogen gene, $\mathrm{S} 203$; on maize, allelopathic compounds, $\mathrm{S} 60$; on maize, seed treatments, S134; protein regulators, characterization, $\mathrm{S} 110$

$-F$ virguliforme: growth and sporulation, tem- 
perature and light, S45 PCR quantification, $\mathrm{S} 101$; on soybean, crop rotation, $\mathrm{S} 84$; on soybean, quantification on roots, S154; virulence, fingerprint analyses, S101

Fusicladium effusum

-azoxystrobin and salicylhydroxamic acid effects, S144

-fungicide sensitivity, assay, S212

Fusicladosporium carpophilum, on stone fruits, trifloxystrobin effect, S207

Fussler, L., 571

Gabor, B., S53

Gabriel, D., S48, S56, S131, S136, S181

Gadoury, D., S15, S56, S109, S125, S190

Gaeumannomyces graminis, on wheat, DAPG sensitivity, Washington, S85

Gagnevin, L., 919

Galagan, J., S185

Galbraith, D. W., S174

Gale, L. R., 159, S56

Gallegly, M., S67, S68

Gallup, C. A., S56, S198, S211

Galvani, C., S44

Gambhir, A., S57

Gamliel, A., S159

Gamliel-Atinsky, E., S57

Gandhi, K., S57

Gao, L., S57, S97

Gao, Q., S33

Gao, X., S57, S123

Garbelotto, M., 137, S111

Garber, N. P., S57

Garces, J. A., S102

Garcia, E., S135

García-Cano, E., 618

Garcia-Garza, S., S162

Gardiner, S. A., S58

Gardiner, S. E., S114

Garibaldi, A., S64, S128

Garneni, S., S166

Garran, S., S30

Garrett, K., S137, S149, S191

Garvin, D. F., S24

Garza, A. A., S58

Garzon, C., S58, S75

Garzon-Tiznado, J., S162

Gasparoto, M. C., S19

Gasparoto, M. G., S21

Gautam, P., S58

Gautier, A., 1271

Gavassoni, W. L., S178

Gbenle, G. O., S115

Geagea, L., S50

Geider, K., S108

Geils, B. W., 413

Geiser, D., S7, S98, S146

Gelernter, W., S151

Gene ontology, microbe and host interaction, S40

Genger, R. K., S58

Genomics

- comparative, future, S7

- host pathogen interaction, proteomic approach, S186

Gent, D. H., 1107

Genzlinger, L. L., S49

Geotrichum candidum, on peach and nectarine, California, S175

Gerhardt, D. J., S59

Gerik, J. S., S59

German, T. L., 45, S114, S136, S171

Geurkink, B., S103

Ghabrial, S., S55, S119, S194

Ghanbarnia, K., S59

Ghimire, S., S59, S68

Giammaria, S. L., S201

Gibberella spp.

- G. circinata, birth and maturation of pathosystem, S187
-G. zeae: ascospore germination, factors, 504, 956; ascospore viability, solar radiation, S113; on barley and wheat, deoxynivalenol concentration and disease intensity, S113; on barley, wheat, potato, and sugar beet, genetics, 969; Trichoderma for biocontrol, S29; on wheat, head blight and deoxynivalenol, S150

Gibson, A., S208

Gibson, D. M., S76

Gijzen, M., 1179, S90

Gilbert, J., 504, 956

Gilbertson, R. L., 1029,

Gildow, F. E., 1233, S124

Giles, C. G., S141

Gillen, A. M., 1212

Gillespie, J., S45

Gilliland, S. E., S107

Gillings, M., 1060

Gillis, I. M., S59

Giordano, L. B., 618

Giraldo, M. C., S59

Giraud, T., S208

Gitaitis, R., S113, S211

Giusti, A., S186

Gladiolus, Fusarium corm rot, treatment, S207

Glandorf, D. C., S85

Glasner, J., S40, S98

Glawe, D., S15, S59

Gleason, M. L.,S66, S72, S118, S147, S149, S153, S156, S174

Glenn, A. E., S60, S119

Glenn, D. L., S125

Gliocladium roseum, biocontrol agent, detection assay, S155

Glomerella cingulata, on blackberry, Mexico, S131

Glover, K., S150

Glucksman, S. J., S18

Glycine tomentella, on soybean, resistance, S34

Gnanamanickam, S. S., S60, S215

Goates, B. J., S60

Gochez, A., S30, S60

Godon, J., S132

Goetz, K. E., S214

Gold, S., S33, S154, S185

Golzar, H., 886

Gomes, P. J., S196

Gongora-Canul, C., S60

Gonzalez, A., S42, S134

Gonzalez, E. T., S61, S191

Gonzalez, F., S54

Goodin, M., S98

Goodwin, P. H., S31

Goodwin, S. B., 101, S170, S202

Gordillo, L., S164

Gordon, T., S187

Goss, E. M., S61, S63

Goswami, R. S., S57, S86, S100

Gottwald, T. R., 1060, S23, S41, S48, S121, S181, S196

Goudarzi, A., S18

Gout, L., 321

Govers, F., S69

Gowda, M., S114, S148

Gowda, S., 592, S174

Grabau, E., S215

Graham, J. H., 1060, S20, S53, S55, S196

Graham, M. Y., S61

Graham, T. L., S61, S133

Grajales, A., S134

Grandillo, S., S98

Grando, M. S., 153

Granke, L. L., S61

Grape

-Aureobasidium pullalans, ochratoxin A, 1261

-bacteria and nematodes, management in California, S122

-bitter rot, infection factors, 580

—black rot, control, S207
- crown gall, biocontrol, 1218

- cytochrome, transcriptional regulation, S37

- decline, fungal pathogens in Iran, S108

- disease diagnosis, protein arrays, S52

- downy mildew, host and nonhost resistance, 776

- downy and powdery mildew, fungicide sensitivity, S214

-Eutypa lata, virulence factors, 222

- gray mold: fungicide, S148; sexual recombination, Hungary, 1312

-Pierce's disease, epidemiology in Texas, S210

- powdery mildew: bud overwintering, Italy, 148; diversity in North America, Europe, and Australia, S25; epidemic and advisory system, $\mathrm{S} 190$; fungicide, $\mathrm{S} 140$; resistance, S13; resistance screening, S29; sunlight effect, S15

-rhizosphere bacteria, California, S121

— trunk diseases: Mexico, S67; survey, France, 571

Grapevine fanleaf virus

— dagger nematode association, France, 942

—variability, California, S116

-variant in Washington, S103

Grapevine leafroll-associated virus-1, molecular variability, S57

Grapevine leafroll-associated virus 3

-mealybug transmission, S159

- mealybug vector, 1093

Grasses, diseases and climate change in prairies, S191

Grau, C. R., S70, S203

Gray, S. M., S33, S61, S62, S124, S154, S170

Greenberg, E., S101

Greene, M. D., S72

Greeneria uvicola, on grape, infection factors, 580

Greer, C. A., S33

Greif, C., 776

Gremmeniella abietina, on Pinus contorta and $P$. sylvestis, Sweden, S22

Greve, L. C., 222

Griffin, G., S7

Griffin, T. S., S115

Griffith, J. J., S61

Griffiths, H. M., S62

Grimme, E., S62

Grisham, M. P., S62

Groopman, J., S182

Grosman, J., 571

Gross, D., S94, S131, S171

Gross, H., S94

Gross, N. W., S62

Gross, S., S86

Grossman, R. B., S52

Groves, C. L., S55

Groves, R., S55, S62, S114, S147, S156

Gruber, B. R., S62

Grunwald, N., S61, S63, S121, S130, S196

Gu, G., S63

Guan, S., S63

Guaragna, M., S76, S78

Guasco, J., S101

Gubler, D., S135

Gubler, W. D., 222, S26

Gudmestad, N. C., 901, S10, S34, S205

Guerrero-Herrera, M., S117

Gugino, B. K., S63

Guignardia citricarpa, on tangerine, black spot, S137

Guiltinan, M., S98

Gulati-Sakhuja, A., 1340, S63

Gullino, M., S64, S128

Gulya, T. J., 926

Gulyamova, T. G., S64, S155

Guner, N., S91

Guo, B., S36, S44, S166

Guo, J., S89, S168, S175

Guo, L., S198 
Guo, M., S158

Guo, Q., 803

Guo, T., S204

Gupta, G., S142

Gutierrez, D. L., S64, S138

Gutierrez, S. P., S64

Gutiérrez Mañero, F. J., 451, 666

Gwinn, K., S96, S118, S149

Gwinn-Giglio, M., S40

Ha, Y., S64

Hadwiger, L. A., 372

Hagan, A. K., S24, S30

Hagen, C., 1029

Hahn, M. G., S163

Hajimorad, M., S65, S96

Halbert, S. E., 387, S97, S129

Halbrendt, N. O., S209

Hallen, H., S33

Halloran, J., S115

Halseth, D. E., S62

Halterman, D., S18, S37, S93

Hamada, W., S65

Hambleton, S., S18

Hamelin, G., 653

Hamelin, R. C., S52

Hamilton, J., S38

Hammerschmidt, R., S49, S140, S179, S202

Hammond, J., S90

Hammond, R. W., S65

Han, C., S65, S144

Han, K., S121

Han, L., 1118

Han, S. (New Mex.), S35

Han, S. S. (Korea), 436, S88

Han, Y., S121

Handelsman, J., S8

Hanna, J. W., S192

Hanna, L., S50

Hannick, L., S40

Hanse, B., 942

Hansen, E., S187, S196

Hanson, L. E., S65, S115

Hanson, S., S87, S130, S150

Hansson, P., S22

Hao, J., S49, S179

Happstadius, I., 215

Harakava, R., S97

Haralson, J. C., S65

Harimoto, Y., 1099

Harman, G. E., S174

Harms, A., S18

Harp, T. L., S53

Harpin, V., 1156

Harrington, T. C., S82, S101, S174

Harris, K., S91

Harris, L. J., S152

Harris, S. D., 695

Harrison, B. D., S193

Harrison, S. A., S56

Hartman, G. L., S34, S47, S66, S95, S119, S123 S147, S154, S195

Hartney, S. L., S66

Hartung, J. S., 359, S89

Hasey, J. K., S66

Hashim-Buckey, J., S148

Hasing, T., S96

Hass, I. R., S48

Hassell, R. L., S14, S156

Hau, B., S104

Haudenshield, J. S., S66, S95

Haugen, L., S77

Hausbeck, M. K., 1075, S61, S67, S129, S140

Havey, M., S9, S91

Hawes, M. C., S169

Hayakawa, Y., S13

Hayasaka, T., 1038

Hayashi, Y., S145

Hayes, M., 781, 792
Hayes, R. J., S14, S83

Haynes, K. G., S140

Haywood, J., S149

Hazard, N., S120

He, J., S63, S72

He, S., S177, S192

He, Z. (Maine), S115

He, Z.-H. (China), 1291

Heckmann, A. B., S163

Hed, B., S207

Heidel, G. B., S173

Heiman, D. I., S185

Hein, J., S191

Held, B. W., S66

Helft, L., S21

Helianthus annuus (see also Sunflower)

-Sclerotinia head rot, quantitative trait loci, 926

Helicotylenchus multicinctus, on banana, cover crops, S166

Hell, K., S109

Helliwell, E., S176, S202

Helminthosporium solani, on potato, mineral effect, S206

Hemerocallis spp., bleach solution for sanitation, $\mathrm{S} 133$

Hemnani, K., S66, S72, S147, S149

Henderson, D., S132

Henriquez, M. A., S66

Herman, M. A. B., 1226, S191

Hernandez, D., S140

Hernandez, E., S67

Hernandez-Martinez, R., S67

Hernandez Nopsa, J., S67

Hershman, D. E., 999

Heterodera spp.

- H. filipjevi, on cereal, first in North America, S176

-H. glycines: on soybean, root growth response, peptides, S132; on soybean, tillage intensity and crop sequence, S169; tillage effect on populations, S204

Hickman, L., S43

Hicks, T. E., S83

Hietala, A. M., 51

Hilf, M. E., S10

Hill, C. B., S95

Hill, J., S65

Hill, S. N., S67

Hillman, B. I., S43

Hinton, D. M., S16

Hladky, L. L., 1340, S172

Ho, H. H., S67

Hobbie, S., S140

Hobbs, H. A., S47

Hoch, H., S44, S45, S191

Hoeschele, I., S165

Hofstadler, S., 1156

Hogan, D. A., S37

Hogenhout, S. A., S39, S41

Hokanson, S. C., S170

Holb, I. J., 79, S67, S68

Holbrook, C., S36

Hollier, C. A., S211

Hollingsworth, C. R., S139

Hollosy, S. I., S202

Holmes, G., S10, S49, S68

Holshouser, D., S125, S217

Holtz, B. A., S27

Holtz, G., S127

Honda, Y., 1165

Honeycutt, C. W., S115

Hong, C., S10, S67, S68, S84, S85

Hong, J. C., S32

Hood, M. E., S208

Hoogenboom, G., 1066, S115

Hooks, C. R., S124, S166

Hoon, H., S81

Hopcroft, D. H., S110

Hopkins, D. L., S169
Horn, B. W., S109

Horner, M. B., S114

Hornok, L., 69

Horowitz Brown, S., S69

Horsch, R., S2

Horseradish, root infection, $\mathrm{S} 178$

Horvath, B. J., S154

Hoshi, A., 769

Hosta spp., bleach solution for sanitation, S133

Hosta virus $X$, sequence comparisons, S45

Host-pathogen interaction, ADP-ribosylation, S195

Hotchkiss, M., S25

Hovmøller, M. S., S69, S107

Hoy, J. W., S211

Hoy, M. A., S32

Hsieh, Y., S14, S143

$\mathrm{Hu}, \mathrm{C} ., \mathrm{S} 69$

Hu, H., S142, S215

Hu, J., 926, S215

$\mathrm{Hu}, \mathrm{X} ., \mathrm{S} 69$

Huang, C. (Fla.), S69

Huang, C.-J. (Taiwan), 830

Huang, G.., S148, S174

Huang, H., S16

Huang, J., S34

Huang, K., S108

Huang, L., 289

Huang, Q., S89

Huang, T., S69

Huang, X., S41

Huang, Y., S70

Hudler, G., S7, S112, S168, S185, S198

Huerta-Espino, J., S54

Huettel, R., S41, S152, S212

Huge, R., S61

Hughes, G. L., 810

Hughes, G. R., 702

Hughes, M. A., S70

Hughes, T. J., S70, S203

Huguet, J., S191

Hulbert, S., S88, S137, S177

Humeau, L., 919

Hunter, S. C., S120

Hurtado-Gonzales, O. P., 688, 1075

Hussey, R. S., S148, S174

Huttlin, E., S18

Hwang, J., S70

Hyakumachi, M., 159, S105

Hydrangea, phyllody:

- phytoplasma infection, cover photo, July

- phytoplasma, malformed flowers, genes, 769

Hydrangea macrophylla

- disease resistance, S108

-leaf spot, resistance and shading density, S89

Hylurgus ligniperda, Ophiostomataceae association, California, S82

Hymowitz, T., S34

Hyten, D., S117

Iacobellis, N. S., 1060

Ichiishi, A., 397

Ichinose, Y., 1218

Identification of species, DNA markers, bacterial pathogens, S141

Idris, A. M., S27, S70

Iida, Y., 1099

Illicium verum, antifungal activity of fruit, S70

Im, Y., S81

Imai, S., S71

Impatiens necrotic spot virus, genetic analysis, S122

Impullitti, A. E., S71, S203

Inderbitzin, P., S71, S175

Ingels, C., S26

Ingram, D. M., S78

Ingram, J., S71

Inguagiato, J. C., S207

Inman, S., S60, S215 
Inoue, K., 1218

Iorizzo, M., S57, S97

Ipomoea spp.: natural habitats in Uganda, cover photo, June; Sclerotinia minor infection, S210

-I. batatas, Rhizopus stolonifer, susceptibility, S49

Ireland, A., S40

Iriarte, F. B., S71

Iris yellow spot virus, distribution in Georgia, S211

Irish, B. M., 894

Irrigation, Phytophthora irrigata and P. hydropathica, fundamental nursery, S68

Isakeit, T., S57, S76, S211

Isard, S., S18, S48, S113, S163

Ishiguro, K., 1038

Ishihara, H., S71

Ishii, H., 585

Ishii, Y., 769

Ishikawa, K., 464

Islam, M., S72

Ivanovic, M., S72

Ivors, K., S23, S56, S72, S132, S211

Iwanami, T., 592

Iyer-Pascuzzi, A. S., 289

Izadpanah, K., S20, S130

Jabaji, S., S43

Jabaji-Hare, S., S206

Jack, A. H., S73

Jackson, K. L., S177

Jackson, T. A., S20, S25

Jacob, D., 270

Jacobi, V., S126

Jacobs, J. J., S73

Jacobs, J. L., S202

Jacobs, J. M., S73

Jacobsen, B. J., S62, S109, S112

Jacques, M.-A., 1060

Jahn, C. E., S73

Jahn, M., S33

Jahng, K., S86

Jaime-Garcia, R., S73

Jang, E., S74

Janisiewicz, W., S74, S77

Jankovics, T., 529

Janse, J. D., 1060

Jansky, S. H., 680, S74

Jany, J., S161

Japonica, Indica crossed with, recombinant, S75

Jarausch, W., 153

Jatropha curcas, nut disease, S164

Jeamjitt, O., S97

Jeffers, S. N., S40, S70, S102, S133

Jeger, M., S189

Jenkins, D. M., 1045, S85, S120

Jenks, B. M., S74

Jeong, B., S76

Jeong, J., S178

Jeong, K., S39, S74

Jeong, R., S74

Jermakow, A. M., S13

Jeske, H., S70

Jesse, L., S118

Jesus, W. C., S141

Jeung, J., S88

Ji, P., S43, S84, S177

Jia, H., S58

Jia, Y., 1305, S44, S75, S87, S88, S92

Jiang, H., 289

Jiang, S., 585

Jianjun, H., S128

Jimenez, P., S30

Jiménez-Díaz, R. M., 167, 709, 1019, S75, S131

Jimenez-Gasco, M., S51, S58, S75, S131

Jin, X., S75

Jin, Y., S136

Jinek, A., S75

Jirak, J. C., S75
Jo, Y.-K. (Mass.), 108, S207

Jo, Y.-K. (Texas), 1297, S17, S76

Jochum, C. C., 695

Joda, A., S117

Joe, A., S76

Johnson, A., S210

Johnson, C. E., S150

Johnson, C. S., S122, S216

Johnson, D. A., S35, S48, S71, S142

Johnson, E. (N.Y.), S191

Johnson, E. G. (Fla.), S76

Johnson, K. B., S76, S96, S151, S156

Johnson, K. N., 810

Joly, D. L., S52

Jomantiene, R., S44, S168

Jones, A. D., 330

Jones, C. A., 205

Jones, D. C., S173

Jones, J. B., S7, S20, S53, S169

Jones, R. (U.K.), S191

Jones, R. A. C. (Aust.), 1280

Jones, R. W. (Md.), S61, S76, S143

Jordan, R., S76, S78

Joshi, B. D., S77

Joshi, M., S191

Juanqui-Valencia, M., S197

Julia, J. F., S199

Jung, G., 108, 1297, S17, S76, S207

Jung, H.-Y., 769

Jurgens, J. A., S66

Jurick, II, W. M., S77

Justesen, A. F., S69

Juzwik, J., S77, S201

Kachroo, A., S33, S55, S74

Kachroo, P., S33, S74

Kaczmarczyk, J., S55

Kadoiri, A., S145

Kageyama, K., 159

Kagiwada, S., 769

Kahn, B. A., S210

Kairu, G., S77

Kakizawa, S., 769

Kalleshwaraswamy, C. M., 541

Kamas, J., S23

Kanda, A., 1165

Kaneshiro, W. S., S78

Kanetis, L., 205

Kang, B., S78, S81

Kang, J., S82, S136

Kang, L., S165

Kang, S., 436, S80, S82, S98, S114, S185, S215

Kang, Z., S177

Kankanala, P., S80

Kanobe, C., S134

Karaffa, L., 1312

Karaoglanidis, G. S., 443, 736, S16

Karasev, A., S61, S69, S78, S170

Karchani-Balma, S., 1271

Karimova, K. M., S64

Karpisek, A. D., S78

Karugia, G. W., 159

Karunakaran, M., S78

Kasem, S., S79

Kasson, M. T., S207

Katan, Y., S159

Katawczik, M. L., S79

Kathiria, P., S79

Kawaguchi, A., 1218

Kawasaki, Y., S79

Kaye, A. C., S79

Kearney, S., S25

Keel, C., S94

Keeler, K. H., S137

Keinath, A. P., S91, S116

Kelemu, S., S197

Kell, T., S110

Keller, N., S12, S57, S69, S182

Kemerait, R. C., Jr., 1066, S115
Kenaley, S. C., S216

Kendall, A., S194

Kennedy, G. G., S79

Kennelly, M., S56, S80

Kent, A. C., S133

Kerbalaeva, A. M., S155

Kern, J., S80

Kerns, J. P., S80, S211

Khan, M. F., S80

Khang, C., S80

Khodjibaeva, S. M., S64, S80, S155

Kido, K., 181

Kilaru, S., S19

Killiny, N., S81

Kim, B., S76

Kim, C., S81

Kim, D., S78, S78, S86, S88, S120

Kim, E., S76

Kim, G., S74

Kim, H., S81, S82, S177, S203

Kim, J., S81, S86, S120, S138

Kim, K., S120

Kim, M. (Gwangju, S. Korea), S81

Kim, M. (Jeonnam, Korea), S83

Kim, M. (Seoul, Korea), S86, S120

Kim, M.-S. (Idaho), S191, S192

Kim, S., S78, S78, S82

Kim, W. (Korea), S74

Kim. W.-S. (Canada), 673, S46

Kim, Y., S39, S39, S74, S78, S81, S87, S178, S205

Kimura, M., 397

Kinard, G., S76, S89

Kingsley-Richards, S. L., S42

Kinkel, L., S82, S136, S140

Kinzer, K. M., S82, S164

Kirk, S., S53

Kirk, W., S49, S179

Kiss, L., 529

Kistler, H., S56, S122

Kitajima, E. W., 977, 1199, S48, S134

Klassen, W., S180

Kleczewski, N. M., S82

Kleinhenz, M. D., 562, S19

Kleinhofs, A., 910

Klessig, D., S74

Klittich, C., S176

Klopfenstein, N. B., 413, S192

Klosterman, S. J., S14, S78, S83, S185

Kluepfel, D. A., S47, S52, S61, S66, S101, S121, S122, S175, S191

Knapp, S. J., 926

Knepper, C. P., S83

Knight, L. M., 181

Ko, S., S83

Kobayashi, R., S178

Kobes, N., 571

Koch, P., S17, S207

Koczan, J. M., S83, S102

Kodama, M., 458

Kodira, C. D., S185

Koenig, J. L., S83

Koganezawa, H., 464

Kogel, K., S164

Kohl, L. M., S83

Kohn, L., S193

Koike, S. T., S173

Koivunen, M., S16

Koizumi, S., 159

Kokaew, J., S97

Kokalis-Burelle, N., S71

Kolander, T. M., S84

Kolb, F. L., 87

Kolkman, J., S39

Köller, W., S42

Kolmer, J. A., S24, S117

Kolomiets, M. V., S57, S210, S212

Kon, T., 1029

Koné, D., S84 
Koné, S. B., S47, S84

Kong, P., S68, S84, S85

Korban, S. S., S119

Koski, A., S25

Koten, C., S203

Kousik, C. S., S10, S14, S85, S156, S159

Kousik, S., S10

Kovács, G. M., 529

Koval, N. C., S70, S203

Kovalchuk, I., S79

Kövics, G. J., 1312

Kozik, A., S195

Krampis, K., S165

Krasnoff, S. B., S76

Kraus, J., S160

Krause, C., S27, S93, S116

Krenz, J. E., 555

Krishna Kumar, N. K., 541, S136

Kristensen, K., S107

Kromer, U., 504, 956

Kruger, E. L., S62

Krupa, S., S97

Ktenz, B., S70

Kubicek, C. P., 1312

Kubisiak, T. L., S13

Kubota, K., 181

Kubota, M., S105

Kubota, R., 1045, S85, S120

Kuldau, G. A., 330, S172

Kulshrestha, S., S33

Kumagai, L., S52

Kumar, L. P., S11

Kumar, N. K. K., 45

Kung, Y.-J., 848

Kunta, M., S85, S98, S131

Kurata, T., 1099

Kurle, J., S84, S97, S105, S154

Kurowski, C., S87

Kurtzman, C., S74

Kutin, K., S85

Kwak, Y., S85

Kwon, B., S86, S120

Labavitch, J. M., 222

Labbé, C., S206

Lacerda, G. G., S29

Lacy, G. H., S7

Laflamme, G., S22

Lagos, L. E., S134

Lakshman, D. K., S86

Lakso, A. N., S15

Lalancette, N., S207

Lalli, D. A., S114

LaMondia, J. A., S63, S207

Lamour, K. H., 688, 1075

Lampinen, B. D., S27

Lamppa, R. S., S57, S86

Lanclos, D., S211

Landa, B. B., 167, 709, S75, S131

Landa, L., S200

Lang, J., S38

Lange, H. W., S24, S30, S86, S191

Langston, D. B., S151

Larkin, R. P., S86, S115, S208

Larrañaga, S., S87

Larsen, H., S126

Larsen, J. E., S139

Larsen, M., S63

Larsen, R., S87

Lartey, R. T., S87

Latinovic, J., S72

Latinovic, N., S72

Latorre, B. A., S46, S51

Lawrence, K. K., S32, S143

Lawrence, K. S., S109, S146

Lawrence, T., S6

Lazarovits, G., S9

Leach, J., S31, S38, S44, S71, S88

Lea-Cox, J., S68, S84
Leandro, L., S45, S46, S60, S101

Leboldus, J. M., S87

Lebsky, V., S200

Le-Coutois, V., 59

Leduc, D., S149

Lee, D., S166

Lee, F. N., S44

Lee, H., S160

Lee, I., S88

Lee, J. (Daegu, Korea), S88

Lee, J. (Gwangju, Korea), S78, S87

Lee, J. C. (Calif.), S82

Lee, K., S88, S120

Lee, L.-Y., S208

Lee, M., 315

Lee, R. F., 387, S97, S129

Lee, S., S87, S88, S120, S121

Lee, Y. (Chungnam, Korea), S120

Lee, Y. (Suwon, Korea), S83S

Lee, Y.-H. (Seoul, Korea), 436

Le Floch, G., S161

Legrand, D., 919

Lehman, B. L., S113

Lehman, S. (Okla.), S107

Lehman, S. M. (Canada), 673

Lehmann, C., S18

Lehtonen, M. J., 1190

Leifsonia xyli, on sugarcane, yield loss, S62

Leisner, S., S93, S179

Leng, Y., S88, S180

Leonard, R. C., S58

Leptosphaeria spp.

-L. biglobosa: on Brassica napus, subclade in Australia, 321; on oilseed rape, cover photo, March

-L. maculans, on Brassica napus, polymorphic markers, S59

Leslie, J. F., 250, 992

Letter to the Editor, bacteria as biological weapons, 1060

Lettuce

-big vein, symptoms, S14

-big vein disease, antioxidant system, S135

-Verticillium wilt, protein-tagged isolate, 871

Lettuce big-vein associated virus, on lettuce, Mirafiori lettuce big-vein virus comparison, 464

Leucine-rich repeat domains, $\mathrm{R}$ gene products, S2

Leung, H., S31, S44, S88, S145

Leveillula taurica, on onion, alternative hosts, Idaho and Oregon, S139

Lévesque, A., S38

Lévesque, C. A., S184

Levi, A., S91

Levy, L., S93, S100, S111, S179

Lewandowski, D., S45

Lewis, C., S121

Lewis Ivey, M. L., S50

Li, D., S144

Li, F., 1156

Li, G. (Canada), S59

Li, G. H. (Beijing, China), 803

Li, H., 321

Li, H. (Beijing, China), S155

Li, H. (Guangzhou, China), S35

Li, H. (Okla.), S89

Li, H. (Shaanxi, China), S153

Li, H. X. (Wash.), 427

Li, J., S89, S215

Li, R., S89

Li, S., 695, S89, S95, S155, S159

Li, W., S10, S111

Li, X., S89, S90, S92, S203, S204

Li, Y., S44, S89

Li, Z., S132

Liao, H., S47

Liberti, D., S90

Lichens-Park, A., S56
Lieten, S., S103

Liew, E. C. Y., 250

Light, D. M., S119

Lilium spp., Botrytis leaf blight, systemic resistance induced, 830

Lim, G., S83

Lim, H., S90

Lim, J., S120

Lima, G., 1261

Lin, F., S90, S179

Lin, H., S37, S45, S47, S156

Lin, Y., S34

Lindeberg, M., S40, S90

Lindholm, C., S212

Lindquist, J. L., S204

Ling, K., S91

Ling, P., S166

Lipps, P. E., 999, S26

Little, C. R., S28, S34, S58

Liu, B., S92

Liu, D., 1291, S82

Liu, E., S34

Liu, G., S75, S92

Liu, H., S63, S89, S92

Liu, J., S128, S151, S166

Liu, L., S91, S92

Liu, M., S174

Liu, S., S35, S93, S168

Liu, T., S128

Liu, W., S92, S128

Liu, X., S90, S93, S174

Liu, Y.-B., 659

Liu, Y.-H., 830

Liu, Z., S37, S93, S168

Livingston, S., S93

Livingston, W. H., S207

Lo, C.-T., S208

Locke, J., S27, S93, S116

Lockhart, B. E., S12, S94

Lomax, J., S40

Long, J., 781, 792

Longlund, J. M., 580

Loper, J. E., 1252, S66, S94, S151

Lopera, C., S94

Lopez, C., S32

López, M. M., 59, 949, 1060

Lopez-Lopez, A., S161

Lord, M., 488

Lorè, A., S64

Lorenzen, J., S61, S170

Lorge, A., S94

Loria, R., S76, S191

Lorito, M., S174

Loschinkohl, C., S9

Lotrakul, P., S64

Lough, T. J., S110

Loughman, R., 886

Lougnon, G., S163

Louws, F., S92, S129, S133

Louzada, E. S., S85

Lozovaya, V., S95, S129

Lu, C., S128

Lu, S., S63

Lu, X., S94, S95

Lunar crop science, soil test, S164

Luo, C.-X., 230

Luo, M., S26

Luo, Y., S95

Lupin, Bean yellow mosaic virus, epidemiological model, 1280

Luster, D., S95, S100, S163

Lutz, J. D., 469

Lygin, A., S95

Lyles, L., S166

Lynch, R. P., S208

Lysobacter enzymogenes

—antimicrobial activity, biocontrol, 695

-biocontrol traits, S178

Lysoe, E., S122 
Ma, J., S28, S95

Ma, K., S87

Ma, L.-J., S96, S185

Maccree, M., S61, S66

MacDonald, J., S5, S56

MacDonald, W. L., S216

Macedo, P. E., S41

MacGuidwin, A. E., S20

Machado, C., S54

Machado, J. C., S102

MacKenzie, J., 345

MacKenzie, S. J., S96

Mackill, D. J., S132

MacMil, S., S77

Macrophomina phaseolina

-isolate analysis, Iran, S11

-PCR assay, S95

- on sorghum, sclerotial germination, S18

Madden, L. (Columbus, Ohio), S83

Madden, L. V. (Wooster, Ohio), 239, 999, S113, S123, S188, S189

Maffia, L. A., 1205, S41

Magnaporthe spp.

-M. grisea: appressorium formation, attachment signals, S205; on rice, sequencing of small RNAs, S114; silicon interaction, analysis, S28; transcription factor, growth requirement, S204; transcription factors, S22; transducin beta-like gene, S202

-M. oryzae, AVR-Pita metalloprotease, analysis, $\mathrm{S} 88$; interfacial complex, $\mathrm{S} 80$; protein secretion, analysis, S148; on rice, appressorial penetration and silicon, 1038; on rice, avirulence gene, S44; on rice, geldanamycin and genes, $\mathrm{S} 108$; on rice, gene expression analysis, stress, S216; on rice, global gene expression, stress, $\mathrm{S} 100$; on rice, glycoproteins, spore germination, S145; on rice, haplotype diversity, 1305; on rice, population differences, 436; on rice, secretion mechanisms, effector proteins, S59; on turf, temperature and leaf wetness, S80

Mahaffee, W. F., 1107, S96

Mahal, G., S77

Mahmood, T., S96

Mahmoudi, B., S11, S138

Mahoney, N. E., 222, S119

Mahovic, M., S216

Maier, K., S115

Maios, C. M., S206

Maize (see also Corn)

—aflatoxin-resistant inbreds, markers, S26

-Aspergillus flavus and Colletotrichum graminicola, resistance, S210

-bacterial stalk dry rot, China, S166

-land races, aflatoxin, Mexico, S117

—leaf chlorosis, gammabacteria, Mexico, S179

-mycotoxins, spectroscopy, S171

-Northern leaf blight, genetic loci, S39

-Penicillium mycotoxins, ensilaged, 330

- southern leaf blight, resistance loci, 315

Maize dwarf mosaic virus, sweet corn, foliar disease relation, $\mathrm{S} 105$

Maize fine streak virus

—in Drosophila cells, S39

-quantitation, temperature transcription, S171

Majerczak, D. R., S41

Malapi-Nelson, M., S65, S96

Malek, A. A., S37

Maling, T., 1280

Malmstrom, C. M., S189

Malnoy, M., S114

Malvick, D., S22, S71, S84, S97, S201, S203

Management

—challenges in Mariana Islands, S112

—challenges in programs, S196

-organic cropping system, damping-off, 562

- strategic decisions and changing agriculture, S188

—water quality, irrigation, plant health, S68
Manandhar, R., S124

Mandal, B., 196

Mandal, S., 196

Mandariaga, C., S135

Mangandi, J., S96

Mango, anthracnose, resistance in Florida, S155

Mangravita-Novo, A., S169

Manihot esculenta, root rot, Nigeria, S11

Manjunath, K. L., 387, S97, S129

Mann, H. S., S57, S97

Manning, V. A., S97

Manoch, L., S97, S164

Manosalva, P., S44

Mansfield, M. A., 330, S98

Mansour, M. F., S148

Manulis-Sasson, S., S169

Manuscript preparation, author's guide, 7

Mao, Y., S165

Marchand, G., S206

Marco-Noales, E., 949

Marek, S., S29, S77, S160

Marelli, J., S98

Marepally, S., S98

Margosan, D. A., S148

Mariano, A. G., 1084

Marín, M., S134

Marine, S. C., S216

Markell, S. G., 632, S100, S107

Marlow, G. C., S136

Marois, J. J., S48

Maroof, M., S117, S165

Marqués, J., 337

Marquez-Villavicencio, M., S98

Marra, R. E., S208

Marrero, G., S98

Marrone, P., S16

Martin, K., S98

Martin, R. R., S57, S99, S103, S160

Martinez, N., 196

Martínez Medina, A., S20

Martinez-Ramirez, J., S99, S127, S199

Martins, E. C., 977

Martins, R. B., 1205

Martyn, R. D., S1

Marui, J., S22

Maruthachalam, K., S14

Marx, D. B., S56

Masiri, J., S99, S110

Mask, R. A., S173

Masseret, B., S98

Massman, J. M., S99

Masumi, M., S130

Masunaka, A., 187

Matheron, M. E., S99

Mathew, F. M., S100

Mathioni, S. M., S100, S216

Matsuda, Y., 529

Matthews, B. F., S159

Maumy, M., 571

Maurhofer, M., S94

Maurice, S., S132

Mavrodieva, V. A., S100

Maximova, S., S98, S147

Maxwell, N. L., S173

May-De Mio, L. L., S100

Mayfield, A. E., S48, S70

Maymon, M., S57

Mayton, H., S130

Mazurek, S. A., S74

Mazzola, M., S100

Mbofung, G., S45, S101

McCallister, J., 359

McClean, A. E., S101

McClung, A., S75, S92

McCouch, S. R., 289

McDonald, B. A., 932, 1326, S188

McDonald, G. I., 413, S192

McDonald, M., S101, S194

McEvoy, J. L., S77
McFarland, K. A., S207

McGehee, J. E., S211

McGhee, G. C., S22, S101

McGovern, R. J., S18, S102

McGrath, M. J., S102

McGrath, M. T., S102

McGuire, C., S36

McHale, L., S195

McInroy, J. A., S143

McKenna, F., S51

McKie, P., S166

McLaughlin, D., S183

McLaughlin, I. M., S102

McMahon, M. B., S95

McManus, P., S62, S177

McMullen, M. P., 969, 999

McNellis, T. W., S113, S147

McPhee, K., S15

McRoberts, N., 239, S188

McSpadden Gardener, B. B., 562, S19, S21, S130, S204

Meacham, T., S69

Mecey, C., S177

Medeiros, C. B., S112

Medeiros, F. C., S102

Medeiros, F. H., S102

Medicago truncatula (see also Alfalfa)

—nuclear calcium spiking, symbiotic signaling, S163

Medrano, E. G., S103

Medrano, F. J., S29

Meekes, E., S103

Mehdizadegan, F., S103

Mehl, H., S103, S169, S203

Mehrabi, R., S204

Meinhardt, S. W., S103

Meitl, A., S176

Meksem, K., S93

Mekuria, T. A., S57, S103

Melampsora spp.

-on poplar, DNA barcodes, S52

-on poplar and willow, overwintering in North America, S109

Melcher, U., 960, S17, S189, S190

Melgarejo, L. M., S200

Melia azedarach, phytoplasma, decline, Brazil, S48

Mello, A. F. S., 960, S190

Mello, A. S., S104

Melnick, R. L., S104, S208

Meloidogyne spp., diagnostic protocol, S150

-M. artoellia, on chickpea, Fusarium oxysporum relation, 709

-M. hapla, Pseudomonas chlororaphis as pathogen, hydrogen cyanide, S87

-M. incognita: on Arabidopsis, parasitism genes, S148; citrus-based compound effect, dose response, S71; DIBOA effect, S105; genes for parasitism, RNA analysis, S174; on watermelon, South Carolina, S14

-M. japonica, on Colocasia esculenta, resistance,

Thailand, Vietnam, and Nepal, S117

Melon (see Muskmelon, Watermelon)

Melon necrotic spot virus

-on Cucumis melo, systemically noninfective, 1165

-multiplication and movement, systemic, 181

Melotto, M., S177

Melouk, H., S104

Melton, R., 1156

Mena-Ali, J., S104, S208

Mena-Munguía, S., S99

Mendes, M., S178

Mendioro, M. S., S132

Meng, F., S73, S104

Meng, S., S114

Menge, J. A., 547

Menke, J., S122

Menkir, A., S26 
Mentha arvensis, Verticillium wilt, hosts, S48

Mercado-Blanco, J., 101, 167

Merdinoglu, D., 776

Mergoum, M., 101, 702

Merighi, M., S41

Mersha, Z., S104

Mertely, J. C., S96

Meyer, J. D., S91

Meyer, J. R., S62

Meyer, M. C., 932

Meyer, M. D., S105

Meyer, P. W., S105

Meyer, S. L., S105

Mghalu, J., S105

Miazzi, M. M., S102

Michailides, T. J., 736, S16, S71, S95, S105, S175

Michelmore, R. W., S195

Microbotryum violaceum, on Caryophyllaceae, herbarium survey, S104, S208

Mideros, S. X., S106

Miklas, P., S87

Mila, A., S79

Mila, M., S38

Miles, T. D., S106

Milgroom, M. G., 148, 436, S25

Miller, G. L., S106

Miller, J. F., 926

Miller, M. L., S106

Miller, N., S106

Miller, S. A., 562, S19, S50, S174

Millet, E., 353

Milling, A., S104, S106

Mills, D., S202

Mills Lujan, K., S107

Milus, E. A., 632, S11, S56, S69, S107

Min, K., S74

Minthostachys mollis, antimicrobial activity, S200

Mintz, D., S159

Mio, L. M., S148

Mirafiori lettuce big-vein virus, on lettuce, Lettuce big-vein associated virus comparison, 464

Mirkov, T., S85

Mirlohi, A., 910

Mitani, N., S28

Mitchell, T., S22, S29, S40, S114, S186

Mitchum, M., S93, S132

Mithani, A., S191

Mitidieri, M., S30

Mitra, R., S107

Miyamoto, C., S139

Miyara, I., S107

Miyasaka, A., 159

Miyasaka, S., S117

Mizubuti, E. S. G., 1205, S41

Mlikota Gabler, F., S148

Mmbaga, M. T., S108, S140

Mo, J., S204

Mochizuki, M. J., 547

Mochizuki, T., 181, 1165

Mock, R., S89

Model

-basic reproduction number, dynamics, 239

- gene-for-gene relations, polymorphism, 128

-plant imports, rejection probability, 728

- spore dispersal, crop growth, canopy filtration, 492

-Tomato spotted wilt virus on peanut, weather, 1066

-transmission, host, virus, and vector, S189

— virus detection and yield loss, S189

Mohammadi, H., S108

Mohammadi, M., S108

Molin, W. T., S151

Molina, A. B., S108

Molineros, J. E., S58

Molitor, A., S164

Moll, E., 153

Moll, S., S191

Molneux, R. J., 222
Momol, M., S169

Monaghan, S., 69

Moncrief, I., S77

Monilinia spp

-M. fructicola: benzimidazole resistance, S95; DMI fungicides, molecular characterization, S68; fungicide adaptation, 230; on peach, age effect, S100; on peach, Bacillus as biocontrol, S92; on peach, DMI resistance, New York, S163; on peach, management, Georgia, S25; on peach, resistance monitoring, $\mathrm{S} 12$; on peach, selective medium, $\mathrm{S} 12$

-M. fructigena, on apple: injury factors, 79; weather factors, S67

-M. laxa, on peach, brown rot in Brazil, S148

Moniliophthora perniciosa, on cacao:

-biotypes, S155

- cerato-platanin proteins, S29

-tomato resistance source, $\mathrm{S} 98$

Montero-Astúa, M., S136

Montesino, L. H., S19

Montesinos-Herrero, C., S119

Moore, G. G., S109

Moore, M., S118

Moore, S., S109, S195

Moorman, G., S28, S58, S68, S84

Mora, R., S14, S54, S135

Morales, N. P., S64

Morano, L., S157

Moreno-Valenzuela, O. A., S197

Morente, C., 949

Moretti, A., 69

Morgan, D., S16, S95, S105

Morgan Jones, G., S32

Mori, N., 458

Moricca, S., 380

Moriones, E., 618

Morris, C. E., 1060, S158, S190

Mosquera, G., S59

Motteberg, C. D., S139

Mouen Bedimo, J. A., 1320

Mount, L. L., S109

Mowery, P., S44

Moya, E. A., S109

Moyer, C., S96

Moyer, J. W., S79, S122

Moyer, M., S109, S190

Msikita, W., S110

Mudgett, M. B., S193

Muehlbauer, G. J., S58

Mueller, D., S174

Mueller, J., S195

Muiño, B., S87

Mukasa, S. B., 640

Mukherjee, M., S110

Mukherjee, S. S., S110

Mulches, effect on spaghetti squash, Quebec, S158

Mulder, P., S212

Mule, G., 69

Mullins, R. F., S206

Mullis, K. L., S43

Mullis, S., S113, S211

Mulrooney, R. L., S173

Mumma, E. P., S141

Mumma, P. E., S110

Munch, P., S115

Munck, I. A., S110

Mundt, C. C., 555, 752, S5

Munkvold, G., S46, S167

Murai, N., S64

Murcia, N., 1199

Murillo, J., 260

Murphy, J. (N.C.), S122

Murphy, J. A. (N.J.), S207

Murphy, J. F. (Ala.), S99, S110

Murray, L., S139

Muskmelon (see also Watermelon)

—bacterial wilt, row covers, S118
Muthappa, S., S111, S165

Muthusamy, K., S64

Mycorrhizae, arbuscular, hyphal platoons, S112

Mycosphaerella graminicola

—-fungicides, field trials, S176

— sexual recombination, epidemics, 752

-on wheat, incomplete resistance specificity, 555

Mycotoxin

-aflatoxin: Aspergillus flavus on cotton, 282; contamination reduction, S182; disease redefined, S182; human carcinomas linkage, epidemiology, S182; synthesis regulation, S182

-deoxynivalenol, soil bacterium effect, S72

- detection and quantification, PCR assay, S205

-Fusarium on barley, China, 719

-host-specific protein, Alternaria brassicae, 458

- ochratoxin A, Aureobasidium pullalans on grape, 1261

-Penicillium spp., in ensiled maize, 330

Myresiotis, C. K., 443

Myrfield, M., S10

Myrothecium roridum, on water hyacinth, biocontrol, S115

Mysore, K. S., S13, S111, S160, S161, S165

Myzus persicae, Papaya ringspot virus vector, 541

Nagamura, Y., S28

Nagle, A. M., S111

Naidu, R. A., S11, S57

Naik, M. K., S109

Najar, F., S77

Nakaho, K., 187

Nakajima, T., 159

Nakashima, J., S160

Nakhla, M. K., S93, S111

Nakka, S., S111, S180

Nam, S., S74

Namba, S., 769

Namwamba, F., S210

Nandakumar, R., S112

Nandwani, D., S112

Narasimhan, B., 95

Nash, G. H., 95

Nasim, G., S112

Nasmetova, S. M., S64, S155

Nault, B. A., 1233, S144

Navarez, M., S199

Navarre, D., S33

Navas-Cortés, J. A., 167, 709, S75, S131

Navi, S., S90, S101, S204

Nazar, R. N., S133, S145

Nazareno, N., S112

Ndoumbé Nkeng, M., 1320

Neate, S. M., 969, S43

Neelam, A., 1126

Negi, S., S100

Neher, D. A., S63

Neher, O. T., S62, S112

Neil, T., S96

Nelson, A. H., S112, S168

Nelson, B. D., S113, S126

Nelson, C., S13

Nelson, E. B., 1012, S14, S36, S73, S172

Nelson, R. J., S39, S106, S198

Nelson, R. L., S195

Nelson, R. S., S194

Nelson, S., S98, S131

Nematodes

-on Brassica spp., glucosinolate effect, S116

—fatty acid profiles, host effect, S143

-root knot, ring, and stunt, on Brassica, S150

Nematology

-teaching, specimens, S50

- vegetable and small fruit research, workshops, S63

Neofusicoccum eucalyptorum, host range, Uruguay, $\mathrm{S} 124$

Neonectria spp., on beech, spatial evaluation in Maine, S207 
-N. ditissima, forest pathogen, markers, S208

Neotyphodium coenophialum, biosynthesis genes, ergot alkaloid, S54

Nesmith, S., S65

Newcomb, M., S113

New Pest Advisory Group, exotic pathogens, threat in USA, S142

Ngugi, H. K., S113

Ngwa, T. A., S154

Niazi, A., S20

Niblack, T., S123

Nicholson, P., 69

Nicot, P. C., 529

Nicotiana spp. (see also Tobacco): Pseudomonas syringae, hypersensitivity, cytokinin suppression, 1242; virus proteins, agroinfiltrated, S14

$-N$. benthamiana: Pseudomonas syringae, virusinduced gene silencing, S161; ribonuclease, antiviral, S39

$-N$. langsdorffii, blue mold, resistance, 519

Nierman, W. C., S43

Nikolaeva, E. V., S82

Niks, R. E., 529

Ning, Z., S210

Nirmala, J., 910

Nischwitz, C., S113, S211

Nissan, G., S169

Nita, M., S113

Njambere, E. N., S114

Niiayouom, I., 1320

Njoroge, S., S114

Noel, G. R., S15

Noh, T., S39

Nolan, S., S25

Noll, L. W., S28

Nolte, P., S43, S61

Nordman, D., S29, S134

Norelli, J. L., S114

Norman, D. J., S169

Notteghem, J. L., 1320

Nouri, S., S114

$\mathrm{Nu}, \mathrm{C} ., \mathrm{S} 213$

Nunes, C. C., S114

Nuss, D. L., S168

Nutter, F. W., Jr., S28, S29, S91, S92, S94, S95, S189, S202

Oak

— anthracnose and symbiosis, mini-review, 380

-wilt, threat and response, S187

Oak, S. W., S70

Oberhänsli, T., S115

Obituary, Myron Kendall Brakke, 1056

Obregón, V., S41

O'Brien, J., S77

Obuya, J. O., S115

Ocamb, C. M., S106

Ochoa, O., S195

O'Connell, S., S133

O’Donnell, K., S56, S146

Oerke, E.-C., 760

O'Gorman, D., S145

Oguchi, A., S121

Oh, Y., S22

Ohki, T., 181, 1165

Ohnishi, J., 181

Oidiopsis taurica, on Gazania, Argentina, S29

Oidium neolycopersici

-intraspecific variability, 529

-on tomato, development conditions, 270

Oilseed rape mosaic virus, clones, $\mathrm{S} 180$

Oka, K., 458

Okabe, I., S152

Okada, K., 397

Okalebo, J. A., S204

Okamoto, Y., S145

Okubara, P. A., 837, S175

Okunowo, W. O., S115

Olanya, M., S115
Olatinwo, R. O., 1066, S115

Olaya, G., S116

Oldroyd, G. D., S163

Olivares, C., S75

Olivares-García, C., 1019

Olive

- Pseudomonas savastanoi, pathovar interaction, 815

-Verticillium wilt, spread analysis, 167

Oliver, J. E., S116

Oliver, R. P., 488

Olivera, P. D., 353

Olpidium sp., on citrus and vegetables, molecular identity, S98

Olson, B. R., S152

Olson, H. A., S116

Olson, S. M., S169

O’Malley, P., S66

Omarov, R. T., S39

Omenn, G. S., S3

Omer, M., S93, S116

O’Neill, S. L., 810

Ong, K. (Dallas, Tex.), S116, S150

Ong, K. L. (College Station, Tex.), S211

Onion (see also Allium spp.)

-Botrytis leaf blight, epidemic, 38

- Pantoea ananatis and Botrytis allii, detection, PCR, S64

- purple blotch, thrips damage, S53

Onyeani, C., S117

Oomycete, phenylamide resistant- and -sensitive species, S186

Ophiosphaerella spp.

-O. herpotricha, on bermudagrass, fluorescent proteins, S29

-O. korrae, on Kentucky bluegrass, fungicides, $\mathrm{S} 25$

Ophiostoma novo-ulmi, on elm, parasitic fitness genes, S126

Orange, huanglongbing severity, S19

Orchid, mycorrhizae, diversity, S19

Ordonez, M. E., S117

Ornamentals

- pathogens, MOI-106 for control, S16

— powdery mildews, Italy, S64

-virus threats, Pacific Northwest, S120

Oropeza, C., S199

Ortega, M. A., S117

Ortega-Beltran, A., S117

Ortega-Corona, A., S117

Ortiz, A., S117

Ortiz, C. F., S199

Ortiz-Barredo, A., 260

Ortiz-Ribbing, L. M., S117

Osborne, L., S113, S150

Oshima, K., 769

Ospina-Giraldo, M. D., S61, S143

Osterbauer, N. K., S195

Ostry, M. E., S13, S118

Osunlaja, S., S117

Osuntoki, A. A., S115

Otani, H., 458

Otegui, M., S163

Otero, J., S19

Otrosina, W., S118, S149

Otto-Hanson, L. K., S118, S199

Oude Lansink, A. G. J. M., 728

Oudemans, P. V., S126

Outreach

— changes in world plant pathology, S198

-flat world adaptation, S197

—international agricultural research, history, S198

—Latin America, building bridges, S197

—research in east and central Africa, S197

Owens, A., S118

Owens, K. J., S111

Ownley, B., S96, S118, S149

Oworu, O., S117

Oxelman, B., S208
Padgett, G. B., S211

Padmanaban, A., S119

Padukkavidana, T., S175

Paecilomyces lilacinus, biological nematicide, soil, S211

Pagani, M. C., S212

Pahalawatta, V., S119

Palencia, E. R., S119

Palevsky, E., S57

Palm, M., S152, S186

Palma, M. S., 1084

Palmateer, A. J., S27, S32, S119, S126

Palou, L., S119

Palukaitis, P., S124

Palumbo, J. D., S119

Pan, Q., S90, S179

Panaccione, D., S54, S214

Panax spp.

$-P$. notoginseng, viruses, China, S155

-P. quinquefolium, pathology and seed treatment, S67

Panicum virgatum, endophytes, classification, S21

Pantoea spp.

-P. agglomerans: Erwinia amylovora suppressed by, 1136, S128; host specificity determinants, signals and binding domain, S169

-P. stewartii: on corn, toxins in virulence, $\mathrm{S} 135$; in flea beetle, gene, $\mathrm{S} 41$; isolate aggressiveness, temperature, S92; on sweet corn, resistance, 469; on sweet corn, spread, S91

Papaya leaf distortion virus, new pathotype, threat, 848

Papaya ringspot virus, transmission efficiency, aphids, 541

Papayiannis, L. C., S120

Pappu, H. R., 196, S50, S119, S120

Parada, R. Y., 458

Paradornuwat, A., S47

Pardey, P. G., S188

Pardo, C., S64

Pare, P. W., S102

Paret, M. L., S85, S120

Paris polyphylla, endophyte in rhizomes, S180

Park, J., S77, S121

Park, K., S39

Park, P., 585

Park, S. (Daegu, Korea), S88

Park, S. (Jeonju, Chombuk), S86

Park, S. (La.), S120

Park, S. (Pa.), S82, S114

Park, S. (Suncheon, Korea), S39

Park, S.-Y. (Seoul, Korea), 436, S80

Park, Y. S., S212

Parke, J. L., S121

Parker, D. M., S42

Parker, P., S23, S41, S121, S138

Parker, S. R., S121, S122, S175

Parkinson, N., 1060

Parks, E. J., S122

Parks, R., S122

Parkunan, V., S122, S216

Parry, R. J., S76

Partridge, D., S215

Pasche, J. S., 901, S34, S205

Pasquali, M., S122

Passiflora setacea, leaf spot, new species, S46

Pasteuria nishizawae, in soil, detection with PCR assay, S15

Pastor, C., S119

Pastor-Corrales, M. A., S122

Pataky, J. K., 469, S105

Patel, R. M., 1334

Patterson, F., S6

Patterson, H. A., 860

Pattison, J., S122

Paul, C., S123

Paul, P. A., 999, S26, S51, S113, S123, S141

Paulitz, R. C., 837

Paulitz, T. C., 304, S85, S141 
Pauls, P. P., S72

Paulsen, I., S94

Pavon, C., S123

Paxeley, N. D., 609

Payne, G., S47, S182

Payton, M., S104

Paz, J. O., 1066, S115

Pè, M. E., 315

Pea

-Fusarium solani resistance, mini-review, 372

-Fusarium spp., detection, S100

—root tip infection, DNA secretion, S169

Pea, G., 315

Peach

—brown rot, fungicide adaptation, 230

-leaf curl, Bacillus subtilis for control, S158

- propiconazole translocation, S12

Peanut

- aflatoxin, factors, S24

- fungicides, day and night spray, S210

- organic production system, seed treatments, S137

-soilborne pathogens: cropping sequences, S152,

S212; nematode, S41

— stem rot, oxalate oxidase genes, S36

-Tomato spotted wilt virus, epidemic predictive model, 1066

-transgenic, gene flow in field, S215

—viral sequences, sequence tags, S44

—virus survey, Georgia, S113

Pear

—apple scab model, California, S26

-Erwinia species competition, 673

- scab, resistance induced by acibenzolar-Smethyl, 585

Pearson, T. C., S171

Pechy-Tarr, M., S94

Peckham, G. D., S142

Pectobacterium spp., biological differences, $\mathrm{S} 98$

$-P$. carotovorum, on tobacco, secretion system, S82

Pedersen, J. F., S56

Pedley, K. F., S123

Peet, M. M., S133

Peever, T. L., 345

Pegues, M., S30, S146

Peiman, M., S98, S206

Peiter, E., S163

Pelargonium spp.

-Ralstonia solanacearum, nonculturable cell detection, 949

-stem inoculation, cover photo, August, 1052

Pelargonium zonate spot virus, immunodetection, coat protein, $\mathrm{S} 63$

Peña, E., S14, S135

Peng, Q., S143

Peng, Y.-L., S198

Penicillium spp.: ethanol fermentation coproducts, S167; multiple mycotoxins, silage, 330

$-P$. digitatum, resistance to fludioxonil and pyrimethanil, mechanisms, 205

$-P$. expansum, on apple, fludioxonil and pyrimethanil resistance, 427

$-P$. solitum, on apple, polygalacturonase production, S77

Pentalonia nigronervosa, Banana bunchy top virus vector, factors, 743

Percich, J. A., S22, S201

Pereira, A. S., S112

Pereira, G. G., S29

Peres, N. A., 345, S96, S160

Pereyra, S., S29, S123, S157

Pereyra de la Iglesia, M. T., 451

Perez, C. A., S124

Perez, E. A., S124

Perez, J. M., S119

Perez, K., S33, S124

Pérez-González, A., S199
Perez-Martinez, J. M., S126

Perkinsiella saccharicida, Fiji disease virus vector, assay, 810

Perna, N., S40, S73, S98

Peronospora spp.

$-P$. farinosa, on spinach, resistance locus and molecular marker, 894

$-P$. hyoscyami, on tobacco, Cuban isolates, $\mathrm{S} 87$

-P. sparsa, on blackberry, detection in Mexico, S131

-P. tabacina: genetics, North America and Europe, S23; on tobacco, Actigard effect, S207; on tobacco, resistance, 519

Peronosporomycetes, plant and fungus interaction, signaling, S72

Perry, K., S61, S124

Peter, K., S124

Peterson, C. A., 1179

Peterson, G. L., S125

Peterson, M. T., S178

Peterson, P. D., S5

Pethybridge, S. J., S189

Petiard, V., S98

Petrisko, J. E., S125

Pettigrew, W. T., S151

Peyer, P., 1326

Pfeifer, G., S117

Pfiffi, S., S164

Phaeosphaeria nodorum, on wheat, genetics in mid-USA, 101

Phakopsora spp.

-P. meibomiae, on legume, description, $\mathrm{S} 163$

$-P$. pachyrhizi: cell wall habitat, S95; pattern relation to forecast, S18; on soybean, damage quantification, S141; on soybean, gene expression, S159; on soybean, host range, S147; on soybean, light effect, S89; on soybean, modeling and occurrence in Iowa, S90; on soybean, pathogen-responsive proteins, S120; on soybean, PCR assays, S66; on soybean, penetration strategy, S49; on soybean, rainfall, S48; on soybean, resistance, S89; on soybean, urediniospore adhesion, S163

Phaseolus spp. (see also Bean): rust, resistance in wild populations, S199

-P. vulgaris: anthracnose, new race in North Dakota, S86; Cucumber mosaic virus aphids and transmission efficiency, 1233; curly top virus, resistance, S87; Fusarium and Rhizoctonia spp., root rot in North Dakota and Minnesota, S57; soybean cyst nematode, growth effect, S126

Phialaphora spp.

$-P$. gregata, on soybean: latent infection, S203; monoculture, S203

$-P$. gregata, on soybean, microscopic characterization, $\mathrm{S} 71$

Phibbs, A., S59

Philion, V., S125

Phipps, P., S125, S215, S217

Phoenix dactylifera, brittle leaf disease, novel RNAs, 337

Phoma sclerotioides, on alfalfa, North American populations, S173

Phragmidium violaceum, on blackberry, epidemiology in western USA, S96

Phylogeny

—ascomycota, S184

—basidiomycota, S184

-fungi: S183; subcellular structure importance, S183

—oomycota, S184

Phymatotrichopsis omnivora

—on alfalfa, genomic approaches, S160

-on cotton, root rot, $\mathrm{S} 77$

Physalospora vaccinii, on cranberry, taxonomic classification, $\mathrm{S} 126$

Phytophthora spp.: on asparagus, characterization in Michigan, 1075; on asparagus, symptoms, cover photo, October; database, model for network, S215; domain encoding genes, S76; ecology and pathogenesis, S187; on European beech and lilac, S168; on Fraser fir, cultural system, S132; genetic diversity, S206; genomics, markers, S23; hardwood forests in Appalachian Mountains, S102; historical review, S196; ornamental nurseries, irrigation, S84; ornamentals, management, S121; on ornamentals, North Carolina greenhouse, S116; on ornamentals, survey in Tennessee, S140; on stream bait, North Carolina, S72; variations in populations, forest watershed, S70

- P. capsici: on chile, heat effect, S139; on chile pepper, race-specific resistance, 867; flumorph effect, resistance and inheritance, S128; on Fraser fir, new host, S129; fungicide sensitivity in isolates, S116; on pepper and cucurbits, persistence in Texas, S211; on pepper and squash, Muscodor albus for control, S30; on squash, cover crops, S84; on squash, phosphorous acid for control, S177; survival and spread, Peru, 688; on tomato, salinity-induced predisposition, S128; in water, epidemiology, S61; on watermelon, fungicides, S10; world effect to vegetable industry, S197

-P. cinnamomi: genetic diversity, multi-locus sequence, S98; survival in green waste, 547

-P. citricola, $P$. cactorum comparison, on beech, inoculation method, S112

genetic diversity, multi-locus sequence, $\mathrm{S} 98$

-P. erythroseptica: mefenoxam resistance, S34; on potato, metalaxyl sensitivity, S62

$-P$. hedriandra, on rhododendron, Pennsylvania, S82

-P. infestans: carbohydrate esterase gene family, S143; case study, S196; culture medium, S148; enzyme coding genes, S61; genetic diversity in Andean region, S134; on potato, genes, S66; on potato, organic and conventional fields, Netherlands, S69; on potato, Venezuela, S24; potato cell defense reaction, 653

$-P$. kernovoae, New Zealand and UK isolates, S171

-P. megasperma, on Prunus, resistant rootstocks, S141

-P. nicotianae: $\mathrm{CO}_{2}$ effect, $\mathrm{S} 10$; quorum sensing, $\mathrm{S} 85$; on tobacco, new race in North Carolina, S211; on tobacco, variability sources, S56 - P. parasitica, phosphite for control, S43

- $P$. ramoram: algaecides, toxicity, $\mathrm{S} 40$; on bay laurel, factors, S46; coast live oaks, phenolic compounds, S111; diagnostic assay, S179; genotypic diversity, U.S. nurseries, S63; hosts in redwood forest, inoculum source, 860; immunodetection, P. kernoviae comparison, S141; on oak, evolution, S61; recent discovery, S197; on Rhododendron and Viburnum, root stress, S136; on Rhododendron ponticum, UK woodlands, S53; sporulation on roots, S145; Taqman chemistry, diagnostic method, (2006), erratum, 956; testing program, tissue panel, S100; threat in Ireland, S25; tree susceptibility, Canada, S75; viability, slug passage, S121

-P. sojae: resistance genes, $\mathrm{S} 125$; on soybean, chemotaxis, S133; on soybean, detection, S201; on soybean, resistance genes, S165; on soybean, suberin and resistance, 1179

- P. tritici-repentis, on wheat, resistance analysis, 702

Phytoplasma

-apple, resistance in apomictic rootstocks, 153

—on chile pepper, $\mathrm{S} 130$

-contingency gene regulation, S168

- genome architecture, S44

— genome architecture, phage attack, S168

-lethal yellowing, insect vectors in Mexico, S199

—pigeon pea witches'-broom, citrus huanglong- 
bing association, Brazil, 977

—vegetable crops, Mexico, S200

Phytotoxins, coronatine, Arabidopsis protein complex, S177

Picard, Y., 919

Picea abies, rust, PCR monitoring, Phomopsis relation, 51

Picton, D., S100

Pilgeram, A. L., S139

Pine

-longleaf: prescibed burns and fungal infection,

S149; root damage, S118

—white, climate change effect, S191

Pineapple

-black rot, calcium oxide for control, S31

- heart rot, Dickeya relations, S98

Pinus sp., rhizobacteria, protection for Arabidopsis, 666

- $P$. contorta, gall rust, water relations, $\mathrm{S} 172$

$-P$. radiata, pitch canker, spore deposition in California, 137

- $P$. resinosa, management, stand complexity, S118

-P. strobus, blister rust, resistance in western USA, 413

Pinzon, D., S64

Pipatpongpinyo, W., S117, S125, S204

Piriformospora indica, on barley and Arabidopsis, resistance, $\mathrm{S} 164$

Pizzatti, C., 148

Planococcus ficus, Grapevine leafroll-associated virus 3 vector, 1093

Plant medicine, University of Florida program:

-clinical trials, S18

- emerging profession, S102

Plantard, O., 942

Plasmodiophora brassicae, on crucifers, pathotypes, Canada, S31

Plasmopara viticola, on grape:

—resistance host and nonhost, 776

-zoosporogenesis, S72

Plata-Caudillo, J. A., S67

Ploetz, R., S70, S119, S126, S155

Plourde, K. V., S126

Plum pox virus

-basic reproduction number, model, 239

- detection techniques, S54

Poа аппиа, anthacnose, topdressing, S207

Podosphaera spp.

- P. macularis, on hop, binary power law, 1107

-P. xanthii: on cantaloupe, biopesticides and management, S99; on pumpkin, fungicide sensitivity, S102

Poghosyan, A., S200

Pohl, K., S145

Pokharel, R. R., S126

Polack, G. W., S175

Polanco, L., S52

Poland, J., S39

Polashock, J. J., S126

Poleatewich, A. M., S126

Polek, M., S178

Poleroviruses, cucurbit-infecting, China, S144

Pollution, river, nematodes as bioindicators, S35

Pomella, A. W., S102

Pontim, B. A., S178

Populus spp.

-P. balsamifera, Septoria canker, Canada, S87

- P. tremuloides: hypoxylon canker, management,

S13; toti-like virus, Minnesota, S94

Porchas, M., S99

Poromarto, S., S126

Porras-Alfaro, A., S19

Porter, L., S35, S127, S142, S186

Posos-Ponce, P., S99, S127, S199

Postharvest pathology, green and blue molds of citrus, control, S119

Postinikova, E., 1156, S142

Post-pathogen interaction, genetic analysis, S195
Potato (see also Solanum spp.)

-bacterial pathogens, detection, Washington, S142

-black dot: tuber born inoculum, S71; vegetative conpatibility groups, variability, 901

- cell reaction to Phytophthora infestans, 653

- common scab: new strain in Michigan, S49; tomography scanning, 1118

-cyst nematode, detection: NanoChip technology, S93; with PCR, S111

- early blight, taxonomic predictivity, 680

- early and late blight, sustainability of system, S115

-late blight: control in Brazil, S112; Cymoxanil effect, S199; regional prediction, S149; resistance, S37; resistance evaluation, S134; resistance factors, $\mathrm{S} 130$; resistance gene $R B, \mathrm{~S} 18$; signaling components, S93

—organic, management, S58

-pathogens, detection assay, S115

- powdery scab, status in Egypt, S156

- purple top, leaf roll virus relation, vectors, Mexico, S162

- purple top syndrome, phytoplasma, Montana, S88

-Rhizoctonia solani, defense genes and resistance, light, 1190

-soilborne diseases: composts, S86; management, S208

-Streptomyces spp., txtAB operon, 405

- tuber necrotic ringspot, Potato virus $Y$ association, S170

—Verticillium wilt, resistance, S74

—virus, resistance, S33

- virus unknown, detection, South America, S9

-warts, plasmon resonance, $\mathrm{S} 49$

—wild species, genepool, S57

Potato leafroll virus

- on hairy nightshade, inoculum source in Pacific Northwest, 985

-phloem limitation, S124

Potato spindle tuber viroid, protein phosphorylation, S65

Potato virus $Y$

-aphid vector, on hairy nightshade, S190

—diversity in industry, S61

- potato zebra chips symptom, S162

—resistance conferred by, pepper gene, S124

- storage long term, S62

-on tobacco, Idaho, S69

Potin, P., 653

Powers, K. L., S140

Prasher, S. O., 1118

Prathuangwong, S., 1252, S15, S28, S79, S127

Pratt, R. C., S41, S127

Pratylenchus spp.

-P. neglectus, detection in soil, S175

$-P$. penetrans, on maize, DNA quantification, S123

-P. scribneri, chemotaxis, $\mathrm{S} 16$

Presting, G. G., S141

Preston, G. M., S191

Pretorius, M. C., S127

Preuett, J., S210

Price, J. A., S173, S212

Prior, P., 1060

Pritsch, C., S157

Proano, N., S96

Proffer, T. J., S202

Prunus spp.

- detection arrays, comparison, S217

-replant disease, rhizosphere in California, S47

Prusky, D., S107

Pruvost, O., 919, 1060

Pryor, B. M., S38, S149, S213

Pseudendoclonium submarinum, fungal pathogen of, S206

Pseudocercospora spp.

-P. adontoglossi, on orchid, detection with PCR, S32
- P. angolensis: on citrus, control in Zimbabwe and Mozambique, S127; on citrus, Zimbabwe, S127; on orchid, detection with PCR, S32

-P. dendrobii, on orchid, culture technique, S32

$-P$. fuligena, on tomato, canopy effect, Thailand, $\mathrm{S} 104$

- $P$. vitis, on grape, penetration process, $\mathrm{S} 121$

Pseudocercosporella spp., on apple, sooty blotch and flyspeck complex, S156

Pseudomonas spp.: Arabidopsis model system, effector action, S193; on bean, new species in Mexico, S146; rhizosphere growth, gene expression, S191; on spaghetti squash, Canada, S158; stress amelioration, S204

-P. chlororaphis: bacterial volatile from, stresses, S39; on cucumber, galactinol effect, S81; proteomic analysis, $\mathrm{S} 81$; volatiles, regulatory genes, relation to Bacillus, $\mathrm{S} 15$

- P. fluorescens: biocontrol agent, potato storage, S147; bioinformatic analysis, S66; on corn, abiotic stress, S130; metabolite production, genomics, S94; protozoan predation protected by, $\mathrm{S} 100$

- P. savastanoi: on olive, pathovar interaction, 815 ; on soybean, races in Illinois, S146

-P. synxantha, biocontrol agent, kinase gene, S52

$-P$. syringae: on bean, kinase and secretion system, colonization, S131; choline and analogs, S37; genome mapping, S90; global regulatory gene, S94; growth in plants, S191; membrane and stigmasterol role, S165; on Nicotiana spp., hypersensitivity suppressed by cytokinin, 1242; pathogenesis and protein secretion, S78; protein translocator, S42; on tomato, effectors and protein targets, S76; on tomato, NDR1 function, resistance, $\mathrm{S} 83$; on tomato, plant activators, defense genes, 1226; syringomycin production, GUS reporter system, S171; type III effector, immunity suppression, S193; type III effector protein, S158; typing techniques, S17; water natural cycle, S190

Pseudozyma spp., biocontrol potential, S206

$\mathrm{Pu}, \mathrm{X} ., \mathrm{S} 35$

Puccinia spp.

-P. graminis: on Aegilops sharonensis, resistance, 353; on barley, allele sequencing, resistance gene, 910; on wheat, bacterial DNA in rust DNA, 115; on wheat, races in North America, molecular markers, S152

-P. horiana, on chryanthemum, detection, $\mathrm{S} 123$

$-P$. melanocephala, on sugarcane, yield effect, S211

- P. pelargonii-zonalis, on geranium, detection in greenhouse, S143

-P. psidii, on guava, Hawaii, S160

-P. striiformis: on barley, quantitative trait locus, resistance, 120; novel population, eastern USA, 632; race identification, infection type, S107; races in USA, S36; on wheat, aggressiveness and epidemics, S107; on wheat, epidemic prediction, S144; on wheat, haustoria sequence tags, S177; on wheat, homeobox-like gene, 1291; on wheat, slow-rusting resistance, temperature, 803; on wheat, weather relation, 609; on wheat, worldwide strains, S69

- P. triticina: on Aegilops sharonensis, resistance, 353; genetics of collections, North and South America, S117

Puckhaber, L. S., S151

Pugliese, M., S128

Pumpkin, viruses in Puerto Rico, S134

Purvis, M. A., S211

Pusey, P. L., 1136, S128

Puthoff, D. P., 1126

Putnam, M. L., S106, S160

Pye, M. F., S128

Pyrenophora spp.

-P. teres, on barley, resistance gene, molecular cloning, S93 
-P. tritici-repentis: global genetic structure, S10; toxin sensitivity, letter to editor, 488; on wheat, genes, S10; on wheat, reactive oxygen species, homeostasis, S97; on wheat, variation in Arkansas, S11

Pythium spp.: chemical growth inhibition, S28; on corn and soybean, soil physical properties, S26; damping-off suppression, composts and carbon, S36; fungicide effect, dosage, S58; new species, phylogeny, S201; soil, tillage effect, S92; variation in Ohio, S26

-P. aphanidermatum: on geranium, fungus gnat effect, S14; on vegetable seedlings, biopesticides and fungicides, S19; zoospores, seed exudate effect, S73

$-P$. oligandrum: biocontrol, factors, $\mathrm{S} 161$; on tomato, bacterial wilt biocontrol, 187; in tomato rhizosphere, molecular characteristics, S161

$-P$. ultimum: on geranium, phosphorus effect, S116; suppression by municipal biosolids compost, 1012; transcriptone analysis, S38

- P. volutum: on bentgrass, temperature effect, S80; on creeping bentgrass, temperature effect, S211

Qandah, I. S., S128

Qi, Y., S210

Qian, J., 781, 792

Qin, L., S168

Qinxiao, M., S128

Qiu, J., S128

Qu, S., 781,792

Qu, X., 405

Quagliotto, L., S162

Quarantine, methyl iodide and sulfuryl fluoride for wood packing material, S159

Que, Z., S90

Quesada Ocampo, L. M., S129

Quirin, E. A., S97

Quist, M., S105

Qutob, D., S90

Ra, D., S88

Raaijmakers, J. M., S100

Rabindran, S., S55

Radi, S. A., 926

Radwan, O. E., S129

Raffaelea spp.

-on laurel, populations, S70

-laurel wilt, detection, S48

Ragazzi, A., 380

Rahman, M., S129

Raies, A., 1271

Raja, J. A. J., 848

Rajashekara, G., S174

Ralstonia solanacearum

- antagonistic bacteria, screening, S175

- biovar 2, host range, 59

-detection: bacteriophage mediated, S85; isothermal amplification, 1045

-on ginger, race 4 detection, S120

- on ornamental plants, detection, S85

-on Pelargonium spp., nonculturable cell detection, 949

—race 3 biovar 2, temperature and epidemiology, S104

-races 1 and 3, differences, S73

- on tobacco, diversity in, S79

-Tobacco mozaic virus relation, harpin, S89

-on tomato: hydrogen peroxide stress regulator, S54; plant response, S106

Ramadugu, C., 387, S97, S129

Ramirez, R., S132

Ramos, C., 815, S129

Ramos Solano, B., 451, 666

Ranathunge, K., 1179

Randall, J. J., S130

Randhawa, P., S215

Rashid, K., S15, S130
Rasmussen, J., S10, S57, S88

Rastegar, M., S130

Rathinasabapathi, B., S28

Raudales, R. E., S130, S204

Rauscher, G., S130

Rav David, D., 270

Raven, P. S., S1

Rayapati, N. A., S103

Raymundo, R., S149

Rearick, E., S152

Rebello, G. D., S131

Rebollar-Alviter, A., S131

Records, A. R., S131

Reddy, S. L., S56, S136

Reddy, V. P., S131

Redinbaugh, M. G., S39, S41

Redlin, S., S103

Redondo, A., S55

Reed, S. M., S89, S108

Rees, J., 108

Regulation

- changes in plant pathology, S195

—plant imports, rejection probability, model, 728

—science-based decisions, S196

Rehfeldt, G., S191

Rehman, S., S185

Reigel, D. G., S15

Reilly, C., S25

Reinsel, M. D., S90

Remesal, E., S131

Remison, S. U., S11

Ren, X., 792

Renault, D., S132

Rendon-Salcido, L., S99, S127

Replogle, A., S132

Resende, R. O., 618

Resistance

-Aegilops sharonensis to leaf rust, stem rust, and powdery mildew, 353

-barley to: stem rust, allele sequencing and resistance gene, 910; stripe rust, high-temperature adult plant, 120

-Brassica napus to Verticillium wilt, loci, 215

- Capsicum annuum to Phytophthora root rot, race-specificity, 867

- chickpea to Meloidogyne and Fusarium spp., 709

— defense response genes, S195

- grape to downy mildew, host and nonhost, 776

- lily to Botrytis elliptica, systemic, 830

-maize to southern leaf blight, trait loci, 315

-nonhost, Nicotiana benthamiana and Arabidopsis thaliana, genes, S111

— pea to Fusarium solani, mini-review, 372

- pear to scab, acibenzolar-S-methyl-induced induction, 585

— pistachio to Alternaria alternata, boscalid, 736

- potato to Rhizoctonia solani, genes and light effect, 1190

-rice to: bacterial blight, gene $x a 5,289$; bacterial leaf streak, harpin fragments, 781

- Screening Center, USDA Forest Service, North Carolina, S26

- soybean to root rot, suberin, 1179

- spinach to downy mildew, locus and molecular marker, 894

- sunflower to Sclerotinia head rot, quantitative trait loci, 926

— sweet corn to Stewart's wilt, 469

- tobacco to: blue mold, 519; Tomato spotted wilt virus, chemically induced, 196

- tomato to Tomato yellow leaf curl virus, factors, 618

-turfgrass dollar spot to fungicides, 1297

-wheat to: Fusarium head blight, trait loci, 87; leaf rust, slow-rusting, 803; Septoria tritici blotch, specificity, 555; Stagonospora nodorum, quantitative trait loci, 886; stripe rust and powdery mildew, homeobox-like gene,
1291; tan spot, races 1 and 5, 702

-white pine to blister rust, western USA, 413

Restrepo, S., S32, S64, S94, S134, S146

Reviewers, acknowledgment of, 4

Rey, J. D., S132

Rey, P., S132, S161

Reyes, H., S95, S105

Rezaee, S., S11

Rhabdoviruses, protein interaction and maps, S98

Rhizobacteria

- growth promoting strains, protection elicited, 451

-IAA sensitivity, S27

Rhizoctonia spp.: diversity, AFLP analysis, Washington, S141; on Lepidium draba, survival analysis, S30; species identification, PCR, 837

$-R$. oryzae-sativae, on rice, population in California, $\mathrm{S} 33$

-R. solani: AG-3, whole genome sequencing, $\mathrm{S} 43$; inhibition by monarda, S149; on potato, defense genes and resistance, 1190; on potato, fungicides, Mexico, S127; quinic acid and phenylacetic acid, S18; on rice, flooding duration, S32; on rice and soybean, anastomosis group-1 IA, 1326; in soil, organic management, S19; on soybean, anastomosis group-1 IA, population structure, 932; on sugar beet, rotation crop effect, S25; suppressed by Trichoderma sp., compost, S128; virulence and biology, genes, S86; on wheat and barley, tillage and inoculum density effect, 304

Rhizosphere, taxa discovery, molecular approach, S136

Rhodococcus fascians, pathogenicity testing, S106

Rhododendron, new dsRNA virus, S138

Rice

-bacterial blight, resistance gene $x a 5,289$

-bacterial blight and blast resistance, Korea, S88

-bacterial streak and yield, harpin fragment effect, 792

-blast: appressorial penetration and silicon, 1038; genomic variation analysis, S87; mating type, S179; population differences in Korea, 436; protein gene, polymorphisms, S44; resistance, gene encoding protein, S90

- defense signaling genes, pathways, S145

-disease resistance in ethylene pathway, S176

-Magnaporthe oryzae, haplotype diversity, Pi-ta locus, 1305

-oxalate oxidases, phylogeny and function, S31

- panicle blight, resistance, $\mathrm{S} 112$

-protein kinase, multiple defense responses, S178

-resistance to fungi, S174

-Rhizoctonia solani, anastomosis group-1 IA, 1326

—sheath blight, quantitative trait loci, S92

—smut, management, S26

Rice, C., S105

Richard, J., S182

Richardson, B. A., 413, S191, S192

Richardson, K., S36

Richardson, P., S68, S84

Richter, B. S., S132

Richter, P. M., 469

Rico, A., 260, S191

Rideout, S., S125, S173, S216, S217

Riely, B. K., S163

Riga, E., S132

Riggs, K. J., S133

Riley, M. B., S12

Riley, T., S23

Rimmer, R., S59

Rinehart, T. A., S89, S108

Rioux, D., S22, S75

Risk assessment, transgenic crops, literature, S40

Ristaino, J., S6, S23, S69

Ritchie, D. F., S133 
Ritieni, A., 69

Rivadeneira, M., S30

Rivard, C. L., S133

Rivera, L. I., S42

Rivera Del Cid, E. B., S18

Rivera-Varas, V., S45, S134

Rivera-Vargas, L. I., S53, S157

Rizzo, C., S100, S216

Rizzo, D. M., 860, S46, S53, S121, S197

Robayo Camacho, E., S133

Robb, J. E., S133, S145

Robbertse, B., S184

Robène-Soustrade, J., 919

Roberts, J. A., S208

Roberts, P. D., S69, S85, S116, S159

Robertson, A. E., S123, S134

Robertson, A. M., S28, S29, S94, S95, S189, S202

Robertson, A. T., S198

Robertson, C. J., 592

Robertson, C. L., S141

Robertson, D., S70

Robideau, G., S184

Rodrigo, R. P., S159

Rodrigues, J. V., S52, S134

Rodrigues Neto, J., 1060

Rodriguez, J. J., S134

Rodriguez, L. M., S64

Rodriguez, M., S123

Rodriguez, S., S157

Rodriguez-Brljevich, C., S134

Rodríguez-Jurado, D., 167

Rodríguez-López, J., 709

Rodríguez-Moreno, L., 815

Rodriguez-Ruvalcaba, R., S199

Roe, B., S77

Roegge, M. D., S117

Roelfs, A., S183

Rohrs-Richey, J., S150, S192

Rojas, A., S94, S134

Rojas, M. R., 1029

Rojas-Jara, M., S135

Rollins, J., S193

Rolshausen, P. (Conn.), S135

Rolshausen, P. E. (Calif.), 222

Roman, L., S14, S135

Romero, C. R., S135

Roncero, M. I. G., 509

Roper, M., S135

Rosa, C., S152

Rosales, I., S14, S54, S135

Rosales-Mendoza, S., S119

Rosas, J. C., S199

Rose, crown gall, biocontrol, 1218

Rosenberger, D. A., S137

Rosenzweig, N., S136

Roskamp, G. K., S117

Ross, D., S68, S84

Rosskopf, E. N., S71

Rotenberg, D., 45, S136

Rothrock, C., S16, S161

Rothwell, N. L., S140

Rott, P. C., S136

Rotylenchulus reniformis

—on cotton, population and distribution, S109

-fungi association, S32

Roubtsova, T. V., S136

Roumagnac, P., 919

Rouse, D. I., S58, S113

Rouse, M. N., S136, S137

Rouxel, T., 321

Rowe, R. C., S184

Royer, M., S136

Ruark, S. J., S137

Rubus spp., marafivirus, S137

Rudell, D. R., 1136, S128

Ruggenthaler, P., S137

Ruggi, A., S43

Rupe, J. C., S16, S161, S201
Rush, C. M., 95, S173, S212

Rush, M. C., 1326, S112

Russo, N. L., S42, S137, S208

Ruzieva, D. M., S64, S155

Rybak, K., 488

Rybak, M., S29, S30, S60, S137

Rygulla, W., 215

Ryu, C., S81, S111, S161, S165

Ryu, Y., S88

Saad, A. T., S50

Saar, D., S50

Sabanadzovic, S., S137, S138, S162

Sackett, K. E., 555

Sackett, W. M., 1233

Saffarian Abbas Zadeh, M., S138

Sagaram, U. S., 592, S81, S138

Saillard, C., 977

Sakai, T., 475

Sako, I., 1165

Sakuno, E., 458

Salas, B., S138

Salazar, C., S134

Salazar, E., S135

Saleh, A. A., S137

Salm, H., 153

Samac, D. A., S54, S139

Sampangi, R., S139

Sampath, R., 1156

Samuels, G., S177

Sanchez, A., S23

Sánchez, J., S200

Sanchez-Soto, S., S199

Sanders, D., S163

Sanders, F., S151

Sanderson, J. P., S14

Sándor, E., 1312

Sandoval, C., S135

Sands, D. C., S139

Sands, J. P., S139

Sanogo, S., S139

Santa Cruz, J. H., S140

Santamaria, L., S140

Santillan-Santana, J., S99, S199

Santos Neto, H., S102

Saponari, M., S178

Sasaya, T., 464

Sattarova, R. S., S155

Saude, C., 1075, S101

Savary, S., 38, 571, S32, S56, S188

Savory, E., S83, S140

Sawyer, T. L., S76

Schaad, N. W., 1156, S47, S142, S215

Schard1, C., S52, S54, S152

Scheffler, B. E., 1126, S159

Scherm, H., 79, S56, S65

Schilder, A. C., S106, S140

Schilling, J. S., S156

Schisler, D. A., S147

Schizaphis graminum, Cereal yellow dwarf virus transmitted by, Cyclophilin, S154

Schlatter, D. C., S140

Schlecht, J., S149

Schmale, D. G., S216

Schmidt, F. J., S52, S62

Schmidt, J., S141

Schmidt, L. S., S27, S47, S141

Schnabel, G., 230, S12, S25, S68

Schneider, B., 153

Schneider, D. J., S90

Schneider, K., S98, S141

Schneider, R. W., 823, S110, S141, S150, S195

Schneider, W. L., 1156, S142

Schneider, W. R., S157

Schoch, C., S184

Schoedel, B., S141

Schoelz, J. E., S14, S52

Scholthof, H. B., S39, S143

Scholthof, K.-B. G., S5, S194
Schroeder, B. K., S48, S142

Schroeder, K. L., 304, 837, S141, S187

Schubert, T. S., S196

Schuenzel, E. L., S47, S142, S215

Schumacher, C. F. A., 760

Schwarz, P. B., S45, S103

Schwartzburg, K. A., S142

Schweigkofler, W., 137

Schwiertz, M., S142

Sclerotinia spp.:carpogenic germination, factors, 1144; on lettuce, biocontrol and chemical strategy, S38; sclerotial survival, 659

$-S$. homoeocarpa: on bentgrass, nozzle and water factors, S80; on bentgrass, resistance inheritance, S206; fungicide resistance, S207; specific-site fungicides, S17; on turf, biogeography, S20; on turf, electricity effect, S76; on turf, fungicide timing, S83; on turf, oxalic acid, S20; on turfgrass, fungicide resistance, 1297; vegetative conpatibility, nitrate-nonutilizing mutants, 108

$-S$. minor, on lettuce, biocontrol, S51

$-S$. sclerotiorum: on bean, resistance screening, S118; on canola, ascospore distribution, S128; genetic diversity, Pacific Northwest, S35; genomics, S193; necrosis and protein characterization, S90; pathogenicity characterization, S90; on pea, infection period, S127; sclerotial production, water potential, S104; on soybean, genomic analysis, S30; on sunflower, quantitative trait loci, 926; survival in composted green waste, 547

-S. trifoliorum, on chickpea, intra-field spread, S114

Sclerotium spp., taxonomic revision, DNA sequence, $\mathrm{S} 174$

$-S$. rolfsii: on hosta, screening method, S174; sclerotium formation, genes, S154; on sugar beet, genetic diversity in Mediterranean, S131

Scocco, E. A., S143

Scortichini, M., 1060

Scott, J. B., S69

Scroeder, J., S139

Scully, B., S44, S166

Seaberg, B. L., S143

Sebacina vermifera, on switchgrass, biomass and productivity, S59

Sechler, A., 1156, S142, S215

Secor, G. A., 969, S45, S134

Seebold, K. W., S143, S212

Seed banks, microbial germplasm, clonal repositories, S183

Seem, R. C., S15, S46, S109, S190

Seemüller, E., 153

Seijo, T. E., S96

Seipke, R., S191

Sekiguchi, H., 187

Sekora, N. S., S143

Selimi, D. A., S143

Sellam, A., 736, S16

Semer, C. R., S18, S102

Semones, S., S60, S215

Seong, K., S122

Sepulveda-Chavera, G., S135

Serra, P., 1199

Servin-Villegas, R., S200

Sessa, G., S169

Settles, M. L., S41

Setubal, J., S40

Seuratia millardetii, on Camellia spp., association, S59

Seyb, A., S169, S204

Seybold, S. J., S82

Seyer, L. A., S143

Seyran, M., S144, S212

Shaffer, B. T., 1252

Shafran, H., S107

Shah, D. A., 1233, S144

Shanahan, J. F., S134 
Shaner, G., S113

Shang, Q., S144, S168

Shankar, M., 886

Sharfman, M., S111

Sharma-Poudyal, D., S144

Sharpee, W. C., S69

Shaw, M. W., 609

Shepperd, W. D., S173

Sherman, A., 600, S107

Sherman, D. J., S217

Shew, B. B., S79, S137

Shew, H., S56, S198, S211

Shi, X., S144, S168

Shiel, P. J., S194

Shim, W., S110

Shimizu, J., S145

Shinjo, A., S145

Shipe, E., S195

Shirsekar, G. S., S145

Shishkoff, N., S100, S145

Shittu, H. O., S145

Shoemaker, R., S117

Sholberg, P. L., S145

Short, D. P., S146

Shtienberg, D., 600, S57

Shu, Q. Y., 1305

Shukla, R., S152

Siampour, M., S130

Siddique, K. H. M., 1280

Siegel, S. P., S146

Sierra, R., S134, S146

Signal transduction, effector-dependent inhibition, avirulence proteins, S192

Signaling, microbial communities, host health, S8

Sikora, E. J., S146

Silagyi, A. J., S102

Silicon, virus friend or foe, $\mathrm{S} 179$

Silva, E. G., S48

Silva-Rojas, H. V., S131, S146, S161, S179

Simard, M., S22, S75

Simeto, S., S124

Simko, I., S130

Simmonds, D., S30

Simon, P., S101

Simon, R., 680, S149

Simpson, D., 69

Sims, A. L., S172

Sinden, M. R., S61

Singh, B., S158

Singh, D. K., S113, S147

Singh, P. K., 101, 702, S147

Singh, R. P., S54

Sinohin, V., S108

Sipes, B., S117

Sires, J. L., S142

Sisson, A. J., S147

Sisterson, M., S147, S156

Sivasithamparam, K., 321

Skantar, A., S111

Skaria, M., S85, S98, S131

Slaminko, T. L., S147

Sledge, M. K., S160

Slininger, P. J., S147

Slippers, B., S124

Smart, C. D., 1226, S24, S30, S86, S124, S130, S191

Smigocki, A. C., 1242

Smilanick, J. L., S148

Smiley, R. M., S176

Smiley, R. W., S175

Smith, A., S148, S191

Smith, D. L., 1118, S148, S212

Smith, D. R., S11

Smith, E. F., S7

Smith, J. A., S13, S48, S70, S73, S109

Smith, K. P., S99

Smith, T., 137

Smither, M., S9

Snook, M. E., S16
Snowdon, R. J., 215

Snyder, W., S132

Soares, D. A., S102

Socha, C., S30

Soika, M. D., S159

Soil fumigation

— acrolein, California crops, S59

-metam-sodium, degradation in soil, S159

-methyl bromide, for Agrobacterium tumefaciens and Phytophthora cactorum, S175

Solanaceous crops, multipathogen detection, S124

Solanum spp. (see also Potato): resistance traits, mapping, $\mathrm{S} 97$

-S. phureja, late blight, gene profiles, S146

- S. sarrachoides, Potato leafroll virus on, inoculum source, 985

Solfrizzo, M., 1261

Solheim, H., 51

Solomon, P. S., 488

Somai, B. M., S91

Somervuo, P., 1190

Song, L., S155

Song, Q., 1126

Songkumarn, P., S148

Sopee, J., S148

Sorghum

-biofortified, Africa program, S2

— grain mold resistance, tetrazolium, S28

- seed infection, S28

—soil microorganism vectors, S56

Souza, D. C., S148

Souza, R. M., S102

Soybean

-Asian rust, chemical attenuation of severity, S141

—Bacillus amyloliquefaciens for biocontrol, S127

-bacterial artificial chromosome library, S204

—brown stem rot, yield, S70

- Carlavirus incidence, model in Puerto Rico, S164

-Carlavirus, whitefly transmitted, Puerto Rico, S134

- Carlavirus incidence, model in Puerto Rico, S164

- Cercospora leaf blight and purple seed, population structure, 823

—cyst nematode, resistance gene, $\mathrm{S} 93$

- foliar diseases, assay technique, S204

—-fungicides and insecticides, yield, S117

-Fusarium and Pythium spp., seed decay and root rot, S16

—gene mapping, molecular markers, S117

-multiple pathogen resistance, oleic acid, S55

-mycorrhizae, cyst nematode, soil pH, S154

—organic cropping system, damping-off, 562

- pathogen and symbiont effect on infection, S129

-Phytophthora sojae, race-specific resistance, genes, S61

-Rhizoctonia solani, anastomosis group-1 IA: 1326; Brazil, 932

-root rot, suberin and resistance, 1179

—rust: atmospheric transport in Minnesota, S97; ecological grouping, S203; fungicide response, S125; fungicides, S146, S178; GIS analysis, S110; mid-Atlantic region, S217; in Puerto Rico legumes, S162; overwintering on kudzu, Texas, S76; phage-displayed peptides, S52; resistance evaluation, S123; resistance inheritance, S122; resistance and metabolic events, S95; temperature effect, biogeography, S203; TOPGUARD effect, S146

-rust resistance: gene silencing, S119; USDA collection, S195

— seedling diseases, seed treatments, S161

—seedling pathogens: soil baiting technique, S165; strobilurin fungicides, S50

- Septoria brown spot, yield loss, S202

— sudden death syndrome: fungicides, S167; infection from root to leaves, S60; monoculture effect, S203; multi-gene genealogies, S201

—viruses, Illinois, S47

—white mold, biocontrol, S179

Soybean mosaic virus

-Alfalfa mosaic virus: mixture, synergism, S96; synergism, mutations, S65

-prevalence in Iowa, S94

Spadaro, D., S64

Spaine, P., S149

Spanu, P. D., S193

Sparks, A. H., S149

Sparks, D., S177

Spatafora, J. W., S184

Spear, R., S177

Spears, B. M., S142

Speck, J., S122

Spiering, M. J., S52

Spiers, J. M., S89

Spinach

- downy mildew, resistance locus and molecular marker, 894

-Fusarium wilt, limestone amendments, S48

-microscopic surveillance, food borne illness, S107

Spiroplasma citri

-on citrus, severity in tree canopy, S104

- genetic diversity of strains, 960

Spolti, P., S149

Spooner, D. M., 680

Spore dispersal, epidemics, mathematical model, 492

Sprague, C. L., S65

Spriggs, E., S149

Springfield, T. N., S149

Squash vein yellowing virus

-watermelon vein decline cause, Florida, S10

-whitefly transmission, S167

Sriariyanun, M., S149

Srinivasan, R., 95, 985

Stacey, G., S52

Stagonospora nodorum, on wheat, resistance and quantitative trait loci, 886

Stamler, R. A., S150

Stanosz, G. R., S11, S110, S150

Stansly, P. A., S159

Starr, J., S116, S150

Staskawicz, B., S192

Steadman, J., S118, S199

Steddom, K., S116, S150

Steeves, J. E., S97

Steffenson, B. J., 353, 910

Steimel, J., S101

Stein, J., S113, S150

Steiner, R., 867

Steiner, U., 760

Steinlage, T. A., S34

Stenger, D., S37, S150

Stensvand, A., S125

Stephens, D. J., S150

Stetina, S. R., S151

Stevenson, K. L., S144, S151, S212

Stevenson, W. R., S201

Stewart, S., S123

Stigmina lautii, on spruce, North Dakota, S82, S164

Stiles, C. M., S32

Stipanovic, R., S64, S80, S151, S155

St. Martin, S., S61, S117, S125, S165

Stockwell, V. O., 1136, S76, S128, S151, S156

Stokes, S., S145

Stone, A., S142

Stone, E., S130, S204

Stowell, L., S151

Stoxen, S. M., S152

St-Pierre, B., S195

Strand, J. F., S26

Strausbaugh, C. A., 1212, S152

Strawberry 
- angular leaf spot, detection assay, 359

- anthracnose, fungicide applications, S96

-anthracnose resistance, plasticulture system, S129

- virus survey in USA and Canada, S99

Strelkov, S. E., S31

Strem, M. D., S17, S208

Streptomyces spp.: mechanisms and pathogenicity, $\mathrm{S} 191$; on potato and soil, quantification, 405 soil, population density and antibiotics, S140; thaxtomin biosynthesis, synthetase, S76

$-S$. scabies: antibiotics and nutrients, S82; on potato, tomography scanning, 1118; soil population, variation, S167

Strickland, J. S., S102

Stromberg, E., S125, S217

Stubbs, G., S194

Stump, W. L., S115

Suanthie, Y., S205

Suárez, C., S104

Subbarao, K. V., 659, 871, 1144, S14, S78, S114, S173, S185

Subramanian, S., S61

Such, M., S142

Sudarshana, M. R., S152

Sudarshana, P., S152

Sudini, H., S152, S212

Suga, H., 159

Sugar beet

-Aphanomyces root rot, factory waste lime effect, S172

- curly top, survey in western USA, 1212

- curly top viruses, resistance, S172

- disease and weed management, interaction, S65

-rhizomania, resistance and storability, S152

Sugarcane, Fiji disease virus, vector rearing, assay, 810

Sugarcane mosaic virus, on maize, chloroplast interaction, S37

Sugawara, K., S152

Sullivan, M. J., S153

Summerell, B. A., 250

Summy, K., S34

Sumner, P., S210

Sun, F., 781, 792

Sun, G., S153, S153

Sun, J., S163

Sun, M., S88, S154

Sun, W., S21

Sun, Z., S174

Sundin, G. W., S22, S83, S101, S102, S202

Sunflower (see also Helianthus annuus)

-rust, races in Canada, S130

Sung, S., S149

Surkov, I. V., 728

Suslow, T. V., S152

Sussman, M., S18

Sutton, T. B., 580, S54, S170

Sutula, C., S186

Svircev, A. M., 673, S46, S158

Sweeney, C., S73

Sweet potato feathery mottle virus, wild hosts, Uganda, 640

Sweet potato leaf curl virus, serological detection, S64

Sword-Sayer, M., S149

Sy, O., 867

Sykes, V. R., S154

Synchytrium solstitiale, on yellow starthistle, maintenance, $\mathrm{S} 214$

Syzygium paniculatum, new disease, Florida, S126

Szabo, L. J., 115, S18, S152, S180

Sztjenberg, A., 270, S57

Szurek, B., S32

Tahan, V., S20

Tahboub, M., S139

Takach, J. E., S154
Takahashi, H., 187

Takemoto, J. Y., S79

Takenaka, S., 187

Takeuchi, T., 475

Takikawa, Y., 1060

Talley, A., S56

Tally, A., S116

Tambong, J., S154

Tamborindeguy, C., S154

Tan, E., S16

Tanaka, C., 181

Tang, E., S154

Tang, S., 926

Tang, Y., S13

Tanguay, P., S52

Tanksley, S., S98

Tanovic, B., S66

Tao, M., S155

Tao, Z., S155

Tarnowski, T. L., S155

Tashpulatov, J. J., S80, S155

Tatalovic, N., S156

Tate, W., 296

Tatineni, S., 592, S138

Tatnell, J., 69

Tavantzis, S., S18, S43, S86

Taylor, K., S25

Taylor, R. J., S34

Teaching

- learning domains, S44

-learning outcomes, S198

— mainstream microbes, S198

-next generation, $\mathrm{S} 7$

-online, interactive discussion, S50

- take-home projects, S49

- technology use in curricula, S198

Te Beest, D. E., 609

Teixeira, D. C., 977

Tellier, A., 128

Temple, S., S114

Temple, T., S76, S151, S156

Tenorio, J., S112

Tenuta, A. U., S18

Teraoka, T., S71, S145

Tesfaendrias, M. T., S101

Tewalt, J. P., S156

Thackray, D. J., 1280

Thammiraju, S., S147, S156

Thaveechai, N., S47

Thekopsora areolata, on Norway spruce: PCR monitoring, DNA pool, 51; symptoms, cover photo, January

Theobroma cacao (see also Cacao)

-endophytes, co-colonization, S208

Therioaphis trifoli, Cucumber mosaic virus vector, efficiency, 1233

Thies, J. A., S14, S156

Thomas, B. R., S87

Thomas, M. R., S13

Thomas, R. H., 1179

Thomas, S., S139, S150

Thomma, B., S45, S185

Thompson, A. L., S134

Thomsett, M. A., 69

Thomthampitak, J., 1252

Thresh, J. M., S188

Thyren, E., S142

Tian, M., S140

Tiburcio, R. A., S29

Tiedemann, A., S72

Tilletia indica

-teliospores, on wheat grains, S60

-on wheat: allantoid sporidia, S125; on wheat, rainfall and temperature, Texas, 95

Timmer, L. W., 345

Tisserat, N., S25, S38

Tobacco (see also Nicotiana spp.)

- cyst nematode, induced resistance effect, S216

-induced resistance responses, variation, S122
-Integrated Pest Management, Cuba, S135

-Meloidogyne incognita, ced-9 antisense, S175

-Pythium root rot, surfactants for control, S143

— stress/defense response, signaling, S74

-Tomato spotted wilt virus, chemically induced resistance, 196

Tobacco mosaic virus

-on Arabidopsis, stomata pattern, microtubular assembly, S137

- resistance gene evolution rate, $\mathrm{S} 79$

Toda, T., S43

Togawa, M., 475

Tohamy, A., S156

Tojo, M., 187

Tolin, S. A., S122, S214

Tomaso-Peterson, M., S157

Tomato

- acibenzolar and silicon, S180

-bacterial speck, copper and plant activators, S24

-bacterial spot: crop residue effect, S43; phosphorous acid control, S169

-Beauveria bassiana, Rhizoctonia disease control, S118

-begovirus, Chile, S135

—crown gall, biocontrol, 1218

- foliar pathogens, compost teas for, S84

-Fusarium wilt, biocontrol, UAR, S51

-hair waste and yield, Florida, S179

-organic cropping system, damping-off, 562

- organic production, management, S133

- phytoplasma, greenhouses in North America, S50

- powdery mildew, development conditions, 270

-Pseudomonas syringae, plant activators and genes, 1226

-Pythium oligandrum in rhizosphere, biocontrol, 187

—-soilborne pathogens, compost teas, S47

-Verticillium pathosystem, defense genes, S133

- viruses, Puerto Rico survey, S42

Tomato chlorosis virus, Tomato infectious chlorosis virus comparison, co-infection, virus transmission, 1340

Tomato ringspot virus, on apple, detection methods, S110

Tomato spotted wilt virus

-in Frankliniella accidentalis, transmission role, $\mathrm{S} 136$

- glycoprotein, transmission inhibited by, 45

-on peanut: El Niño and yield relation, S115; epidemic predictive model, 1066; markers, S36; North Carolina and Virginia, S79

-on tobacco: North Carolina, S38; resistance, chemically induced, 196

-thrip interaction, S17

Tomato yellow blotch virus, greenhouse tomato, Minnesota, S12

Tomato yellow leaf curl virus, resistance factors, 618

Tombusviridae, Pelargonium leafspot, Pelargonium line pattern, Elderberry latent virus, new species, S76

Tombusviruses, forest water, New Zealand, S110

Tomimatsu, G. S., S157

Tomimura, K., 159

Tomography, potato scab, 1118

Tooley, P., S100

Torney, V. C., S180

Torres, C. P., S157, S210, S212

Torres, D., S157

Torres, R., S46

Torres Puyo, C., S157

Torto-Alalibo, T., S40

Toruño, T. Y., S158

Toscano, N., S144

Toussaint, V., S158

Toves, P. J., S158, S164

Toyoda, H., 529

Trail, F., S33 
Trapero-Casas, J. L., 167

Traquair, J. A., S158

Travers, S. E., S137

Travis, J., S113, S207, S209, S126

Tredway, L., S80, S106, S159, S185, S208, S211

Tremblay, A., S159

Trevino, R., S58

Trialeurodes spp., Tomato infectious chlorosis virus vector, efficiency, 1340

Trichoderma spp.: on cacao, trichomes, S17; radish damping-off suppressed by, $\mathrm{S} 105$

-T. koningiopsis, on corn, temperature, S177

$-T$. virens, animal waste application sites, Mississippi, S127

-T. viride, plant defense signaling components, fungal elicitor, S111

Trick, H. N., S43

Trigalet, A., 59

Trigalet-Démery, D., 59

Trigiano, R. N., S89

Triky-Dotan, S., S159

Trinh, M., S52

Triticum monococcum, stem rust, resistant germplasm, S136

Trojan, J., S150

Tropiano, R., S18

Truco, M.-J., S195

Trujillo, C. A., S32

Trummer, L. M., S150

Tsai, C.-W., 1093, S39, S159

Tsay, T., S35

Tsuda, S., 181, 1165

Tsuge, T., 1099

Tsukiboshi, T., S152

Tsushima, S., 475

Tubajika, K. M., S159

Tucker, D., S117, S165

Tucker, M. L., 1126

Tugume, A. K., 640

Turechek, W. W., 359, 1107, S10, S85, S159, S160, S189

Turfgrass

- diagnostic tool, irrigation audit, S151

-dollar spot: epidemic model, S148; fungicide resistance, 1297

-fairy rings, phylogenetic analysis, S106

—pathologist history from 1980, S185

- pathology from 1980 to today, S185

- pathology future, S185

Turini, T. A., S38

Turnip crinkle virus, on Arabidopsis, hypersensitivity and resistance, $\mathrm{S} 74$

Turnquist, A., S52

Tuttle, J. R., S70

Tweddell, R. J., S47, S75, S84, S206

Tylenchulus semipenetrans, on orange, Phytophthora parasitica relation, $\mathrm{S} 131$

Tyler, B., S7, S40, S165

Tzanetakis, I. E., S99, S160

Tzeng, D., S69

Tzfira, T., S169

Uchida, J. Y., S160

Uddin, W., S80

Uekusa, H., 397

Ullman, D. E., 45, S136

Umaharan, P., 421

Umesha, S., S84

Upadhyaya, S. K., S27

Uppalapati, S., S160, S161

Upper, C. D., 1060

Uromyces appendiculatus, on bean, sequence tags, 1126

Urrea, K. E., S161

Ustilago maydis, transcription factor, mutant phenotype, S33

Vaccinium meridionale, diseases, Colombia, S30 Váczy, K. Z., 1312
Vaghchhipawala, Z., S13, S161

Vaillancourt, L., S20, S33

Vaira, A., S90

Val, F., 653

Valadez-Moctezuma, E., S146, S161, S179

Valdebenito-Sanhueza, R., S149

Valdez-Oyervides, A., S162

Valent, B., S59, S80

Valenzuela-Solano, C., S67

Valkonen, J. P. T., 640, 1190

Vallad, G. E., 871, S78, S173

Vallance, J., S161

Valverde, R. A., S64, S138, S162

Van Alfen, N., S86

van den Berg, F., 239

van den Berg, G., S185

van den Bosch, F., 239, 609

Vander Kooi, K., S101

van der Lee, T., 719

van der Werf, W., 728

van Esse, H., S45

van Esse, P., S185

VanEtten, H. D., S169

van Helden, M., 942

van Kan, J. A. L., 1334

van Kooten, O., 728

van Leuwen, H., S195

Van Sanford, D., S20

van Santen, E., S109, S143

Varela, H., S162

Vargas, A., S134, S146

Vargas, J. M., Jr., S185

Varghese, S., S2

Vasquez-Siller, L. M., S162

Vasse, J., 59

Vaz, P., S162

Vázquez-Navarro, J., S99

Vega, B., S162, S163

Vega, M. A., S46

Vega-Sanchez, M. E., S145

Vegetable, solarization in greenhouse, Argentina, S41

Velazquez, P., S30

Velez-Climent, M., S163

Venegas, J., S199

Venkateshwaran, M., S163

Venturia spp.

-V. inaequalis: on apple, ascospore factors, S125 on apple, myclobutanil resistance, Virginia, S216; on apple, resistance, New York, S42 conidia, apple leaf adhesion, 760

-V. nashicola, on Japanese pear, acibenzolar-Smethyl-induced resistance, 585

Venu, R., S148

Venugopal, S., S33

Vera, D. I., S104

Vera Cruz, C., S31, S44, S132

Verbena virus $Y$, component in Verbena necrosis, S160

Verdier, V., S32

Vero, S., S29

Veronese, P., S184, S185

Verticillium spp.: arabidopsis interaction, model system, S184; comparative genomics, S185; life history, S184; molecular analysis, S184

$-V$. dahliae: assay on lettuce, S83; on broccoli and cauliflower, resistance, S114; on cotton, antagonists, S80; genetics, Lebanon, S50; on lettuce, population biology in California, S14; on lettuce, resistance and protein-tagged isolate, 871; molecular variability analysis, S78; on olive, diversity in Spain, S75; on olive, Spain, cover photo, February; on olive, spread analysis in Spain, 167; on pepper and morning glory, nematode co-infection, S139; polymorphic markers, S75; soil colonization, fumigation, S173; on spinach, resistance screening, $\mathrm{S} 163$; tomato responses, S185; on tomato, virulence, S145; V. albo-atrum comparison, gene analysis, S12; vegetative compatibility groups, phylogenetic analysis, 1019

-V. longisporum, on Brassica napus, resistance loci, 215

Vialle, A., S52

Vick, B. A., 926

Vico, I., S77

Vidal-Martinez, V. A., S117

Vidaver, A., S6

Vilgalys, R., S43

Viljoen, A., S108

Villani, S. M., S42, S163

Villarroel-Zeballos, M. I., S163

Villate, L., 942

Vincelli, P, S212

Vincenot, L., 321

Vine, B. G., 1045

Virology, history in 20th century, S193

Viruses

- curtoviruses, weeds in New Mexico, S42

—diseases, immunochemistry beginnings, S194

- ecology, new field, S189

-history 100 years, S186

-hop, epidemiology and management, S189

- movement and spreading effect, S194

-Myron K. Brakke, contributions, S194

—novel virus, dumbcane and peace lily, S94

- potyviruses, exotic, in Florida plants, S111

-ribosomal proteins, host factors, S176

-RNA, detection, S214

-structure, X-ray diffraction and electron microscopy, S194

-vectors, foreign gene, S143

Visarathanonth, N., S97, S164

Visconti, A., 1261

Viteri, D., S134, S164

Von Bodman, S., S135

vonBroembsen, S., S212

Vowell, T. S., S158, S164

Vurro, M., S139

Vyn, T. J., S169, S204

Waalwijk, C., 719

Waigmann, E., S137

Waitea circinata, on turfgrass, fludioxonil and polyoxin-D sensitivity, S37

Walcott, R., S49, S64, S91, S143, S150

Waldrop, T. A., S102

Waldrop, V. C., S52

Walker, A. M., S37

Walker, D. R., S195

Walker, E., 886

Walker, N. R., S29, S148

Walkinshaw, C. H., S118, S164

Walla, J. A., S82, S164

Waller, F., S164

Wallhead, M., S26, S165

Wallis, C. M., S165

Wambugu, F., S2

Wan, A., S36

Wang, B., 296

Wang, D., S59, S165, S180

Wang, G.-L., S56, S145, S148, S194

Wang, H., S165

Wang, J., S132, S141, S165

Wang, K., S111, S124, S161, S165, S166

Wang, L. (La.), S110

Wang, L. (Guangzhou, China), S90, S179

Wang, L. (Nanjing, China), 792

Wang, M., S166

Wang, N., 592, S63, S81, S138

Wang, S., S166

Wang, X. (Beijing, China), S166

Wang, X. (Hangzhou, China), 1305, S44, S88

Wang, X. (N.Y.), S132

Wang, Y., S44

Wang, Z., S166, S215

Wanner, L. A., 405, S167

Ward, T. J., 159, S56 
Ware, S. B., S53

Warfield, C. Y., S83

Wargo, M. J., S37

Warnke, S. E., S154

Watermelon (see also Muskmelon)

—multi-virus infection, patterns in Florida, S159

-Rhizopycnis vagum, decline, S170

—root-knot nematode, grafting as tool, S156

— seed disinfection, chlorine, S150

—vine decline: management in Florida, S85; Puerto Rico, S52

—viruses in Puerto Rico, S134

Watermelon mosaic virus, on squash, plastic mulch effect, S110

Watson, A. K., S75

Waxman, K. B., S147

Wayadande, A. C., 960, S107, S190

Weathersbee, A., S21, S48

Weaver, D., S195

Webb, S., 387, S10, S129, S167

Webber, J., S53

Weber, C., S167

Webster, R. K., 992

Wechter, W. P., S52, S91, S191

Weems, J. D., S167

Wegulo, S., S67, S113, S167

Wehner, T. C., S91

Wei, B., S168

Wei, L., S168

Wei, S., S13

Wei, W., S44, S168

Wei, Y., S168

Weibel, E., S206

Weiland, J. E., S112, S168

Weinthal, D. M., S169

Weller, D. M., S85

Welliver, R., S110

Wen, A., S169

Wen, F., S169

Weng, Z., S174

Weselowski, B., S9

Wessel-Beaver, L., S134

West, L., S60, S215

Westerveld, S. M., S101

Westphal, A., S169, S170, S203, S204

Wheat

-Fusarium crown rot: biocontrol agents, S109; resistance, $\mathrm{S} 125$

-Fusariun damaged kernels, evaluation, S167

-Fusarium head blight: deoxynivalenol accumulation, S67; deoxynivalenol, fungicides, multivariate meta-analysis, 999; environment, 69; quantitative trait loci, 87

—Karnal bunt, rainfall and temperature, Texas, 95

-leaf rust: slow-rusting resistance, temperature, 803; transcript profiling, S24

-Mycosphaerella graminicola, sexual recombination, 752

- powdery mildew, population in eastern USA, S122

- powdery mildew and yellow rust, weather relations, 609

-Rhizoctonia root rot, tillage and inoculum density effect, 304

- Septoria tritici, control in Tunisia,

- Septoria tritici blotch, resistance, 555

-Stagonospora nodurum blotch: genetics, 101; resistance and quantitative trait loci, 886

—stem rust, microsatellite markers, S180

-stripe rust: gene mapping, resistance, S38; resistance and temperature, S41; resistance gene $\operatorname{Yr} 5$, S166

- stripe and leaf rust, resistance in Mexico, S54

- stripe rust and powdery mildew, homeobox-like gene, 1291

- $\tan$ spot: races 1 and 5, 702; resistance gene markers, S147; yield loss, S167

-trichothecene detection, electron capture detection, S172 —virus, RNA interference, S43

—viruses, survey in Texas, S173

Wheat Eqlid mosaic virus, molecular characterization, $\mathrm{S} 130$

Wheat streak mosaic virus, water use efficiency, S212

Wheeler, M. H., S151

Whitaker, V. M., S170

White, D., S24, S170

White, F., S53, S96

White, O., S40

White, T. L., S179, S180

Whitehouse, C. A., 1156

Whitfield, A. E., 45, S136

Whitham, S., S176, S180

Whitten Buxton, K. R., S170

Whitworth, J., S61, S170

Whybrow, A., S53

Wicklow, D. T., S171

Widholm, J., S95

Widmer, T. L., S171, S214

Widrig, A., S93

Wiedemann-Merdinoglu, S., 776

Wigginton, J., S98

Wilce, R. T., S206

Wilcox, W., S15, S109, S135, S190

Williams, J. L., S171

Williams, W. P., S106

Willis, D. K., 45, S136, S171

Willocquet, L., 38

Willoughby, G. P., S74

Willyerd, K. T., S172

Wilson, A. D., S172

Wilson, R. E., 886

Windels, C., S25, S172

Windes, J. M., S125

Windham, A. S., S89

Windham, M., S89, S108

Windstam, S., S172

Wing, R. A., S174

Wingfield, M. J., S124

Wintermantel, W. M., 1212, 1340, S172

Wise, K. A., S205

Wisniewski, M. E., S114

Wisser, R., S39

Wolf, R., S80

Wolinsky, M., S142

Wolken, J. M., S172

Woloshuk, C. P., S47, S81, S203, S205

Wolpert, T. J., S97

Wong, F., S37, S80, S178

Woo, S. L., S174

Wood, bacterial wetwood, incidence in lumber, S172

Wood decay fungi, historic structures, Antarctica, S66

Wood degrading fungi, cellulase effect, S156

Wood, D. F., S17

Wood, S., S188

Woodford, M. R., S110

Woods, M. J., 296

Woods, S. M., 504, 956

Woodward, J. E., S210, S213

Workneh, F., 95, S173

Worrall, J. J., S173

Worrall, J. T., S150

Wraight, S. P., S14

Wright, D. L., S48

Wright, G., S109

Wright, M. G., S124

Wright, R. J., S25, S213

Wroblewski, T., S195

Wu, B. M., 659, 1144, S173

Wu, C., S88

Wu, D., 1305

Wu, H.-W., 848

Wu, T., 781, 792

Wu, X., 781, 792

Wulff, N. A., 977, 1084
Wunsch, M. J., S173

Wyenandt, C. A., S173

Wyman, E. A., 45

Xanthomonas spp.

-X. albilineans, albicidin biosynthesis, S136

-X. axonopodis: on Allium spp., polyphasic characterization, 919; on anthurium, biocontrol, S158, S164; on anthurium, nitrogen effect, S142; on anthurium, resistance genetics, 421; on cassava, pathogenicity determinants, S32; on citrus, copper resistance, Argentina, S30; on citrus, strains B and C, S60; effector genes, bioinformatics, S64; on soybean, avirulence genes, S15; on soybean, protein rpfF role, 1252; on soybean, systemic resistance, S79

$-X$. campestris, black rot, control methods in greenhouse, S86

-X. citri: on citrus, virulence factor, S53; dispersal from fruit, S121; genes and diseases, S53; identification, PCR/electrospray ionization mass spectrometry, 1156; resistance to copper and streptomycin, medium, S20

-X. fragariae, on strawberry: detection assay, 359; hot-water treatment, S160

-X. oryzae: biofilm formation, signal transduction, S74; homologs, effector gene, S71; in rice, genes and resistance, $\mathrm{S} 96$; on rice, harpin fragments, resistance induced, 781; on rice, harpin functional fragments, yield effect, 792; on rice, profiling analyses, 149; on rice, races 6 and 9, S132; on rice, resistance, $\mathrm{S} 217$; on rice, resistance gene $x a 5,289$; on rice, virulence determinants, S39

Xia, X.-C., 1291

Xiang, H., S144

Xiao, C. L., 427

Xiao, K., S140

Xiao, S., S195

Xiaohong, L., S128

Xiaolan, C., S128

Xie, G., S35

Xili, L., S128

Xing, L., S170, S203, S204

Xiong, Z., S169, S174

Xiphinema index, on grape, Grapevine fanleaf virus association, France, 942

$\mathrm{Xu}, \mathrm{J} ., \mathrm{S} 37, \mathrm{~S} 132$

Xu, J.-R., S202, S204, S205

$\mathrm{Xu}, \mathrm{R} ., \mathrm{S} 154$

Xu, S.-C., 1291

$\mathrm{Xu}, \mathrm{T} ., \mathrm{S} 174$

Xu, W. W., S24

$\mathrm{Xu}, \mathrm{X}$. (Ohio), S174

Xu, X.-M. (U.K.), 69

$\mathrm{Xu}$, Y. B., 803

$\mathrm{Xu}, \mathrm{Z} ., \mathrm{S} 174$

Xue, B., S148, S174

Xue, C., S205

Xue, Q., S175

Xue, S., S31

Xylella fastidiosa

—on almond, genetics, California, S156

- on blueberry, nutritional requirements, S33

-on citrus and grape, xylem fluid, S144

- environmental factors, S45

-on grape: chemosensory signal transduction, S44; reservoir hosts, S54; Texas, S212; virulence-related genes, S37

-on Helianthus, Iva, Ambrosia, and Vitis spp., S23

-insect transmission, S81

—on mulberry, plasmid, S150

-in Oklahoma, S212

- pathotype, variation, S35

— signaling system, biofilm formation, S13

—strain groups, Texas, S157

Yadeta, K., S185

Yaghmour, M. A., S175 
Yahyaoui, A. H., S69

Yakabe, L. E., S175

Yamaji, Y., 769

Yamamoto, F., S175

Yamamoto, P., S97

Yan, G. (Oreg.), S175, S176

Yan, G. P. (Wash.), 120

Yan, Z., S155

Yanes, M., S162, S176

Yanez, J., S58, S75

Yang, B., S96, S128

Yang, C., S143, S176, S180

Yang, D., S178

Yang, K., S39, S74, S81, S178

Yang, L., 719

Yang, M., S86, S120

Yang, S., S39

Yang, X., 719, S89, S90, S101, S203, S204

Yang, Y., S176

Yao, C., S176

Yao, J., S177

Yao, Y., S79

Yashiro, E., S177

Yates, I. E., S177

Yeast, on nectarines, S74

Yeh, S.-D., 848

Yeh, Y., S69

Yeon, C., S177

Yersinia pseudotuberculosis, secretion inhibitor, shared with Dickeya, S143

Yin, C., S177

Yin, H., S178

Yin, J., S49, S84, S177

Yin, Q., 781, 792

Yockyeng, R., S208

Yoder, K. S., S133, S216

Yokomi, R. K., 960, S104, S178, S190

Yonghao, L., S108

Yoo, S., S178

Yoon, J., S88

Yoshida, S., 475
Young, C., S63, S77

Young, D., S176

Young, J. M., 1060

Young, J. R., S157, S178

Young, L. D., S89

Young, S., S185

Ypema, H. L., S212

Yu, D., 719

Yu, F., 695

Yu, J. (Beijing, China), S144,

Yu, J. (Ill.), S178

Yu, J.-B. (Kans.), 87

Yu, O., S61

Yu, Y., S174

Yue, B., 926

Yuen, G. Y., 695, S28, S178, S204

Yusibov, V., S55

Zablotowicz, R. M., S9

Zaccaron, M. L., S178

Zadoks, J. C., S187

Zaid, M., S61

Zaini, P., S44, S45

Zaitlin, D., 519

Zala, M., 932, 1326

Zaleta-Rivera, K., 695

Zamani Zadeh, H., S11

Zambino, P. (Calif.), S187

Zambino, P. J. (Idaho), 413

Zamorano, A., S54

Zanotto, E., S102

Zaparoli, G., S29

Zare, A., S130

Zarnowski, R., S69

Zasada, I. A., S105

Zdor, R., S27

Zelaya-Molina, L. X., S131, S146, S161, S179

Zeller, K. A., S179

Zellner, W., S93, S179

Zeng, J., S179

Zeng, W., S177, S179
Zequeira, L., S30

Zernova, O., S129

Zhai, X. R., S153

Zhan, G., S41

Zhang, C., 781, 792, S180

Zhang, G., S167

Zhang, N., S124, S146

Zhang, R., S153

Zhang, S. (Fla), 519, S179, S180

Zhang, S. (Mo.), S74

Zhang, S.-J. (Nanjing, China), 792

Zhang, S.-S. (Kunming, China), 792

Zhang, Y., S155

Zhang, Z. (Kunming, China), 792

Zhang, Z. J. (Beijing, China), 803

Zhao, B., S71, S217

Zhao, J., S180

Zhao, T., S215

Zhao, X., S47, S205

Zhao, Y., S44, S111, S146, S165, S168, S180

Zhong, S., S88, S180

Zhou, J., S154

Zhou, L., S21, S48, S70, S92, S165, S180, S181

Zhou, T., S37, S63, S72, S92

Zhou, W.-C., 87

Zhou, X., S176, S180

Zhou, Y., 803

Zhu, H., S63

Zietlow, C., 45

Zink, R. T., S153

Zitter, T. A., S62

Zolotilina, G. D., S80

Zong, Y., S52

Zouid, R., S65

Zucchini yellow mosaic virus

—on cucumber, infection times and yield, S83

-on watermelon, genes and CAPS markers, S91

Zuñiga-Estrada, M., S162

Zuntini, B., S178

Zwonitzer, J. C., 315 